HETEROCYCLES, Vol. 95, No. 1, 2017, pp. 9-61. @ 2017 The Japan Institute of Heterocyclic Chemistry

DOI: $10.3987 / C O M-16-S(S)$ Publications

\title{
Publication List by Masakatsu Shibasaki (1971-2017)
}

1. S. Yamada, M. Shibasaki and S. Terashima

Novel Olefin Formation in the Thermal Rearrangement of Isocyanide to Cyanide

J. Chem. Soc., Chem. Commun., 1008-1009 (1971)

2. M. Shibasaki, S. Terashima and S. Yamada

Stereochemical Studies. XXI. Studies on $\alpha$-Alkyl- $\alpha$-amino Acids. XV. Application of Thermal Isocyanide-Cyanide Rearrangement to $R$-S Conversion of $\alpha$-Methylphenylalanine

Chem. Pharm. Bull., 21, 552-557 (1973)

3. M. Shibasaki, T. Sato, N. Ohashi, S. Terashima and S. Yamada

Stereochemical Studies. XXIII. Stereochemistry of the Thermal Isocyanide-Cyanide Rearrangement

Chem. Pharm. Bull., 21, 1868-1884 (1973)

4. S. Yamada, M. Shibasaki and S. Terashima

A New Biogenetic-type Cyclization of Citral to $\alpha$-Cyclocitral via an Enamine

Tetrahedron Lett., 14, 377-380 (1973)

5. S. Yamada, M. Shibasaki and S. Terashima

Biogenetic-Type Asymmetric Cyclization. Syntheses of Optically Active $\alpha$-Cyclocitral and trans- $\alpha$-Damascone

Tetrahedron Lett., 14, 381-384 (1973)

6. M. Shibasaki, S. Terashima and S. Yamada

Stereochemical Studies. XXXIV. A Novel Biogenetic-type Cyclization of Citral to $\alpha$-Cyclocitral via an Enamine

Chem. Pharm. Bull., 23, 272-278 (1975)

7. Stereochemical Studies. XXXV. A Biogenetic-type Asymmetric Cyclization. Syntheses of Optically Active $\alpha$-Cyclocitral and trans- $\alpha$-Damascone

Chem. Pharm. Bull., 23, 279-284 (1975)

8. E. J. Corey, K. C. Nicolaou and M. Shibasaki

Simple Stereospecific Routes to 9-epi-Prostaglandin $\mathrm{F}_{2^{a}}\left(\mathrm{PGF}_{2^{\mathrm{g}}}\right)$ and 11-epi-Prostaglandin $\mathrm{F}_{2^{a}}$ J. Chem. Soc., Chem. Commun., 658-659 (1975)

9. E. J. Corey, K. C. Nicolaou, M. Shibasaki, Y. Machida and C. S. Shiner

Superoxide Ion as a Synthetically Useful Oxygen Nucleophile

Tetrahedron Lett., 16, 3183-3186 (1975)

10. E. J. Corey, M. Shibasaki, K. C. Nicolaou, C. L. Malmsten and B. Samuelsson

Simple, Stereocontrolled Total Synthesis of a Biologically Active Analog of the Prostaglandin Endoperoxides $\left(\mathrm{PGH}_{2}, \mathrm{PGG}_{2}\right)$

Tetrahedron Lett., 17, 737-740 (1976)

11. M. Shibasaki, S. Terashima and S. Yamada

Stereochemical Studies. XXXIX. A Novel Method for the Preparation of Optically Active Aldehydes. Syntheses of Optically Active $(R)-(+)-\alpha$-Cyclocitral, $(S)-(+)$-Dehydrovomifoliol, and 
(S)-(+)-Abscisic Acid

Chem. Pharm. Bull., 24, 315-322 (1976)

12. E. J. Corey, K. Narasaka and M. Shibasaki

A Direct, Stereocontrolled Total Synthesis of the 9,11-Azo Analogue of the Prostaglandin Endoperoxide, $\mathrm{PGH}_{2}$

J. Am. Chem. Soc., 98, 6417-6418 (1976)

13. E. J. Corey, M. Shibasaki, J. Knolle and T. Sugawara

A Direct Total Synthesis of Thromboxane B2( \pm )

Tetrahedron Lett., 18, 785-788 (1977)

14. E. J. Corey, M. Shibasaki and J. Knolle

Simple, Stereocontrolled Synthesis of Thromboxane B2 from D-Glucose

Tetrahedron Lett., 18, 1625-1626 (1977)

15. M. Shibasaki and S. Ikegami

Intramolecular Sufenyl Bromide Addition Promising a New Synthetic Route to 9(O)-Thiaprostacyclin

Tetrahedron Lett., 18, 4037-4040 (1977)

16. M. Shibasaki and S. Ikegami

Synthesis of $9(O)$-Thiaprostacyclin

Tetrahedron Lett., 19, 559-562 (1978)

17. D. Horii, M. Kanayama, M. Mori, M. Shibasaki and S. Ikegami

Vasodilation Produced by Prostacyclin $\left(\mathrm{PGI}_{2}\right)$ and $9(O)$-Thiaprostacyclin $\left(\mathrm{PGI}_{2}-\mathrm{S}\right)$ in the Canine Femoral Circulation

Eur. J. Pharmacol., 51, 313-316 (1978)

18. J. Ueda, T. Yanagisawa, M. Shibasaki and S. Ikegami

Synthetic Entry into a New Type of Prostaglandin: $6(9 \alpha)$, 6(11 $\alpha$ )-Dioxido-15S-hydroxyprost-13E-enoic Acid Methyl Ester

Tetrahedron Lett., 19, 2511-2514 (1978)

19. M. Shibasaki, J. Ueda and S. Ikegami

New Synthetic Routes to 9(O)-Methanoprostacyclin. A Highly Stable and Biologically Potent Analog of Prostacyclin

Tetrahedron Lett., 20, 433-436 (1979)

20. Y. Torisawa, M. Shibasaki and S. Ikegami

On the Novel Reactivity of $t$-Butyldimethylsilyl Ether in Prostaglandin Synthesis: Application to Total Synthesis of 11-epi-PGF $2^{a}$

Tetrahedron Lett., 20, 1865-1868 (1979)

21. M. Shibasaki, K. Iseki and S. Ikegami

A Stereo and Regiospecific Route to the Synthetic Intermediate for the Synthesis of 9(O)-Methanoprostacyclin

Chem. Lett., 1299-1300 (1979)

22. M. Shibasaki

Recent Progress in the Total Synthesis of Natural Products

J. Synth. Org. Chem. Jpn., 37, 771-784 (1979) 
23. M. Shibasaki, Y. Torisawa and S. Ikegami Synthesis of the Sulfur Analog of $\Delta^{6}-\mathrm{PGI}_{1}$ Chem. Lett., 1247-1250 (1980)

24. M. Shibasaki, K. Iseki and S. Ikegami

Total Synthesis of the Carbon Analog of $\Delta^{6}-\mathrm{PGI}_{1}$

Tetrahedron Lett., 21, 169-172 (1980)

25. M. Shibasaki, A. Nishida and S. Ikegami

A Novel Synthetic Route to 6-Oxabicyclo[3.1.1]heptane Skeleton

Tetrahedron Lett., 21, 3061-3064 (1980)

26. S. Ikegami and M. Shibasaki

Synthesis and Biological Properties of Endoperoxides, Thromboxanes, Prostacyclins and Leukotrienes

J. Synth. Org. Chem. Jpn., 38, 1037-1052 (1980)

27. M. Shibasaki, K. Iseki and S. Ikegami

An Efficient Synthesis of 7-endo-t-Butyldimethylsilyloxybicyclo[3.3.0]oct-8-en-2-one

Synth. Commun., 10, 545-546 (1980)

28. M. Shibasaki, K. Iseki and S. Ikegami

A Total Synthesis of $d l$-Coriolin

Tetrahedron Lett., 21, 3587-3590 (1980)

29. Y. Torisawa, M. Shibasaki and S. Ikegami

A New Alkyltin (IV)-Mediated Coupling Reaction of Aldehydes to Olefins

Tetrahedron Lett., 22, 2397-2400 (1981)

30. M. Shibasaki

Synthetic Studies on Prostacyclins-Thromboxanes and Polycyclopentanoides

YAKUGAKU ZASSHI, 101, 1073-1091 (1981)

31. A. Nishida, M. Shibasaki and S. Ikegami

Regioselective Transformation of Internal Alkynes to Unsymmetrical Ketones. Novel Routes to Key Intermediates for the Synthesis of Carbapenem and Carbacephem Skeletons

Tetrahedron Lett., 22, 4819-4822 (1981)

32. K. Iseki, M. Yamazaki, M. Shibasaki and S. Ikegami

The Total Synthesis of $d l$-Coriolin

Tetrahedron, 37, 4411-4418 (1981)

33. M. Yamazaki, M. Shibasaki and S. Ikegami

1,2-Carbonyl Transposition of cis-Bicyclo[3.3.0]octan-2-one to Its 3-One Skeleton: Application to Syntheses of $d l$-Hirsutic Acid and $d l-9(O)$-Methanopostacyclin

Chem. Lett., 1245-1248 (1981)

34. M. Shibasaki, A. Nishida and S. Ikegami

A Simple Preparation of (+)-4-Phenylthioazetidin-2-one and an Asymmetric Synthesis of (+)-Thienamycin

J. Chem. Soc., Chem. Commun., 1324-1325 (1982)

35. H. Yokomori, Y. Torisawa, M. Shibasaki and S. Ikegami

A Novel Synthesis of the Sulfur Analog of $\Delta^{6}-\mathrm{PGI}_{1}$ 
Heterocycles, 18, 251-254 (1982)

36. M. Shibasaki, A. Nishida and S. Ikegami

A Mild Method for the Conversion of Propiolic Esters to $\beta$-Keto Esters. Application to the Formal Total Synthesis of $( \pm)$-Thienamycin

Tetrahedron Lett., 23, 2875-2878 (1982)

37. M. Shibasaki, Y. Torisawa and S. Ikegami

A New Method for the Conversion of Aldehydes $\left(\mathrm{RCH}_{2} \mathrm{CHO}\right)$ to Acetylenes $(\mathrm{RC} \equiv \mathrm{CH})$ via 1-Alkenylstannanes. Application to the Synthesis of $9(O)$-Thia- $\Delta^{6}-\mathrm{PGI}_{1}$

Tetrahedron Lett., 23, 4607-4610 (1982)

38. M. Shibasaki, M. Yamazaki, K. Iseki and S. Ikegami

A Simple, Highly Stereocontrolled Total Synthesis of (+)-Hirsutic Acid

Tetrahedron Lett., 23, 5311-5314 (1982)

39. M. Shibasaki and S. Ikegami

Chelation-Controlled Stereo and Regioselective Reactions: Application to Natural Product Synthesis

J. Synth. Org. Chem. Jpn., 40, 602-617 (1982)

40. M. Shibasaki, Y. Torisawa and S. Ikegami

Synthesis of $9(O)$-Methano- $\Delta^{6\left(9_{a}\right)}-\mathrm{PGI}_{1}$ : The Highly Potent Carbon Analog of Prostacyclin

Tetrahedron Lett., 24, 3493-3496 (1983)

41. M. Shibasaki, H. Fukazawa and S. Ikegami

Regiocontrolled Conversion of $\alpha, \beta$-Unsaturated Ketones to Olefins via Allylsilanes: Synthesis of $d l$-9 $(O)$-Methano- $\Delta^{6\left(9_{a}\right)}-\mathrm{PGI}_{1}$

Tetrahedron Lett., 24, 3497-3500 (1983)

42. M. Shibasaki, H. Suzuki, Y. Torisawa and S. Ikegami

$\alpha$-Bromoallylstannanes as Synthetic Tools: Preparations and Reactivities

Chem. Lett., 1303-1306 (1983)

43. Y. Torisawa, M. Shibasaki and S. Ikegami

Novel Reactivities on tert-Butyldimethylsilyl and tert-Butyldiphenylsilyl Ethers; Application to the Synthesis of 11-epi-PGF ${ }_{2 a}$

Chem. Pharm. Bull., 31, 2607-2615 (1983)

44. M. Shibasaki, T. Mase and S. Ikegami

Synthetic Studies on the Capnellane Alcohols: An Efficient Method for the Construction of the C-Ring Bisallylic Alcohol Unit

Chem. Lett., 1737-1740 (1983)

45. M. Yamazaki, M. Shibasaki and S. Ikegami

Novel Synthetic Route to the Key Intermediate for Hirsutic Acid

J. Org. Chem., 48, 4402-4404 (1983)

46. K. Iseki, T. Mase, T. Okazaki, M. Shibasaki and S. Ikegami

Synthesis of $d l-9(O)$-Methano- $\Delta^{6}$-prostaglandin $\mathrm{I}_{1}$

Chem. Pharm. Bull., 31, 4448-4455 (1983)

47. M. Sodeoka and M. Shibasaki

Practical Synthesis of (+)-9(O)-Methano- $\Delta^{6\left(9_{a}\right)}-\mathrm{PGI}_{1}$ : The Highly Potent Carbon Analog of 
Prostacyclin

Chem. Lett., 579-582 (1984)

48. Y. Torisawa, H. Okabe, M. Shibasaki and S. Ikegami

An Improved Route to $(+)-9(O)$-Methano- $\Delta^{6\left(9_{\alpha}\right)}$-prostaglandin $I_{1}$ (Isocarbacyclin)

Chem. Lett., 1069-1072 (1984)

49. T. Okazaki, M. Shibasaki and S. Ikegami

Synthesis of $d l-9(O)$-Methanoprostaglandin- $\mathrm{I}_{1}$

Chem. Pharm. Bull., 32, 424-429 (1984)

50. M. Shibasaki, M. Sodeoka and Y. Ogawa

Stereospecific Synthesis of exo-Trisubstituted Olefins. The Highly Efficient Synthesis of Carbacyclins

J. Org. Chem., 49, 4096-4098 (1984)

51. Y. Ogawa and M. Shibasaki

Selective Removal of Tetrahydropyranyl Ethers in the Presence of $t$-Butyldimethylsilyl Ethers Tetrahedron Lett., 25, 663-666 (1984)

52. A. Nishida, M. Shibasaki and S. Ikegami

The Efficient Synthesis of Chiral Key Intermediates for Monobactam Antibiotics

Tetrahedron Lett., 25, 765-768 (1984)

53. Y. Ogawa and M. Shibasaki

The Intramolecular Thermal Ene Reaction Route to (+)-9(O)-Methano- $\Delta^{6\left(9_{\alpha}\right)}-\mathrm{PGI}_{1}$ Tetrahedron Lett., 25, 1067-1070 (1984)

54. T. Mase, M. Sodeoka and M. Shibasaki

An Efficient Synthesis of Isocarbacyclin Starting from Furfural

Tetrahedron Lett., 25, 5087-509 (1984)

55. T. Iimori and M. Shibasaki

Stereocontrolled Synthesis of (+)-Thienamycin from 3(R)-Hydroxybutyric Acid

Tetrahedron Lett., 26, 1523-1526 (1985)

56. M. Shibasaki, Y. Ishida and N. Okabe

A Novel Synthesis of (-)-Carpetimycin A

Tetrahedron Lett., 26, 2217-2220 (1985)

57. M. Shibasaki and M. Sodeoka

Stereospecific Construction of exo-Tetrasubstituted Olefins. The Efficient Synthesis of Cyano-Carbacyclins

Tetrhedron Lett., 26, 3491-3494 (1985)

58. M. Shibasaki and Y. Ogawa

Total Synthesis of Clavulones

Tetrahedron Lett., 26, 3841-3844 (1985)

59. M Sodeoka, T. Iimori and M. Shibasaki

Stereospecific Synthesis of exo-Allylic Alcohol. An Efficient Asymmetric Synthesis of $(R)$-(-)-2-Acetyl-5,8-dimethoxy-1,2,3,4-tetrahydro-2-naphthol

Tetrahedron Lett., 26, 6497-6500 (1985) 
60. M. Shibasaki and M. Sodeoka

Hydrogenation Reactions Promoted by Arene $\cdot \mathrm{Cr}(\mathrm{CO})_{3}$ Complexes. The Highly Stereo-selective Synthesis of Carbacyclins

J. Synth. Org. Chem. Jpn., 43, 877-890 (1985)

61. M. Sodeoka and M. Shibasaki

New Functions of (Arene)tricarbonylchromium(0) Complexes as Hydrogenation Catalysts:

Stereospecific Semihydrogenation of Alkynes and Highly Chemoselective Hydrogenation of $\alpha, \beta$-Unsaturated Carbonyl Compounds

J. Org. Chem., 50, 1147-1149 (1985)

62. K. Iseki, M. Shinoda, C. Ishiyama, Y. Hayashi, S. Yamada and M. Shibasaki

Synthesis of $(Z)-4,5,13,14-$ Tetradehydro- $9(O)$-methano- $\Delta^{6\left(9_{a}\right)}-\mathrm{PGI}_{1}$

Chem. Lett., 559-562 (1986)

63. M. Sodeoka and M. Shibasaki

Hydrogenation Using (Arene)tricarbonylchromium(0) Complex as a Catalyst

Farumashia, 22, 463-469 (1986)

64. T. Mase, S. Ikegami and M. Shibasaki

The First Total Syntheses of $\Delta^{9(12)}$-Capnellene- $8 \beta, 10 \alpha$-diol and $\Delta^{9(12)}$-Capnellene-3 $\beta, 8 \beta, 10 \alpha$-triol J. Am. Chem. Soc., 108, 2090-2091 (1986)

65. Y. Ogawa, M. Nunomoto and M. Shibasaki

A Novel Synthesis of Prostaglandin $\mathrm{D}_{2}$

J. Org. Chem., 51, 1625-1627 (1986)

66. M. Shinoda, K. Iseki, T. Oguri, Y. Hayashi, S. Yamada and M. Shibasaki

A Convenient Synthesis of $\beta$-Alkynylpropionic Acids from $\beta$-Propiolactones. Synthesis of 4,4,5,5-Tetradehydro- $9(O)$-methano- $\Delta^{6\left(9_{a}\right)}-\mathrm{PGI}_{1}$

Tetrahedron Lett., 27, 87-90 (1986)

67. T. Iimori and M. Shibasaki

Simple, Stereocontrolled Synthesis of $1 \beta$-Methylcarbapenem Antibiotics from $3(R)$-Hydroxybutyric Acid

Tetrahedron Lett., 27, 2149-2152 (1986)

68. T. Iimori, Y. Ishida and M. Shibasaki

On the Stereochemical Course of Vinyloxyborane-Imine Condensation -The Stereoselective Formation of Threo $\beta$-Amino Acid Derivatives-

Tetrahedron Lett., 27, 2153-2156 (1986)

69. T. Mase and M. Shibasaki

Synthetic Studies on Capnellol Family: An Improved Synthesis of $\Delta^{9(12)}$-Capnellene- $3 \beta, 8 \beta, 10 \alpha$-triol and the First Total Synthesis of

$\Delta^{9(12)}$-Capnellene-3 $\beta, 8 \beta, 10 \alpha, 14$-tetrol

Tetrahedron Lett., 27, 5245-5248 (1986)

70. H. Sasai and M. Shibasaki

Total Synthesis of Punaglandin 4

Tetrahedron Lett., 28, 333-336 (1987)

71. A. Takahashi and M. Shibasaki

Stereo- and Regiocontrolled Costruction of 3-Alkyl-cis-bicyclo[4.3.0]non-3-ene Derivatives. An 
Efficient Synthesis of the Potent Homoisocarbacyclin Analog

Tetrahedron Lett., 28, 1893-1896 (1987)

72. G. Iwasaki and M. Shibasaki

Further Studies on the Stereochemistry of Metal Enolate-Imine Condensation Reactions

Tetrahedron Lett., 28, 3257-3260 (1987)

73. M. Mori, Y. Uozumi and M. Shibasaki

Incorporation of Molecular Nitrogen into Amides and Imides by Use of Titanium-Nitrogen Complexes

Tetrahedron Lett., 28, 6187-6190 (1987)

74. M. Shibasaki, Y. Ishida, G. Iwasaki and T. Iimori

Asymmetric Synthesis of the Carbapenem Antibiotic (+)-PS-5

J. Org. Chem., 52, 3488-3489 (1987)

75. A. Takahashi and M. Shibasaki

A New Method for Introduction of Carbon-Carbon Triple Bond at C-13 in PG Synthesis. A Stereocontrolled Synthesis of ZK 96480

J. Org. Chem., 53, 1227-1231 (1988)

76. G. Iwasaki, M. Sano, M. Sodeoka, K. Yoshida and M. Shibasaki

Asymmetric Synthesis of (2R)-2-Hydroxy-2-(2-(Z)-octenyl)-1-cyclopentanone

J. Org. Chem., 53, 4864-4867 (1988)

77. K. Yoshida, S. Nakajima, T. Ohnuma, Y. Ban and M. Shibasaki

Synthetic Approaches toward Mitomycins: Construction of $p$-Quinone Moiety on 1-Benzazocine Derivative

J. Org. Chem., 53, 5355-5359 (1988)

78. M. Shibasaki

Drug Design of Prostaglandins-Basic Strategy-

Host Defense, 5, 126-129 (1988)

79. M. Sodeoka, S. Satoh and M. Shibasaki

Highly Efficient Synthesis of Carbacyclin Analogue. Stereospecific Synthesis of Aryl-Substituted Exocyclic Olefin

J. Am. Chem. Soc., 110, 4823-4824 (1988)

80. M. Mori, K. Kagechika, K. Tohjima and M. Shibasaki

New Synthesis of 4-Acetoxy-2-azetidinones by Use of Electrochemical Oxidation

Tetrahedron Lett., 29, 1409-1412 (1988)

81. K. Yoshida, S. Nakajima, T. Wakamatsu, Y. Ban and M. Shibasaki

A General Procedure for the Catalytic Hydrogenolysis of $N$-Benzylamines under Extremely Mild Conditions

Heterocycles, 27, 1167-1168 (1988)

82. T. Wakamatsu, N. Miyachi, T. Ozaki, Y. Ban and M. Shibasaki

A Novel Antileukemic Sesquiterpene Lactone. Synthesis of Racemic Eriolanin

Tetrahedron Lett., 29, 3829 (1988)

83. M. Mori, K. Kagechika, H. Sasai and M. Shibasaki

An Efficient Formal Total Synthesis of (+)-PS-5 
Chemistry Express, 4, 89-92 (1989)

84. M. Mori, Y. Higuchi, K. Kagechika and M. Shibasaki

Ring Construction of Bicyclic- $\beta$-lactam by Use of Palladium Catalyzed Carbonylation

Heterocycles, 29, 853-856 (1989)

85. A. Takahashi, Y. Kirio, M. Sodeoka, H. Sasai and M. Shibasaki

Highly Stereoselective Synthesis of Exocyclic Tetrasubstituted Enol Ethers and Olefins. A Synthesis of Nileprost

J. Am. Chem. Soc., 111, 643-647 (1989)

86. M. Sodeoka, Y. Ogawa, T. Mase and M. Shibasaki

Efficient Synthesis of Isocarbacyclins

Chem. Pharm. Bull., 37, 586-598 (1989)

87. Y. Uozumi, N. Kawasaki, E. Mori, M. Mori and M. Shibasaki

Novel Lactam Synthesis by Use of a Combination System of Carbonylation and Nitrogenation J. Am. Chem. Soc., 111, 3725-3727 (1989)

88. Y. Nishikimi, T. Iimori, M. Sodeoka and M. Shibasaki

Synthetic Studies of Azadiracthin. Synthesis of the Cyclic Acetal Intermediate in the Naturally Occurring Form

J. Org. Chem., 54, 3354-3359 (1989)

89. N. Miyachi, F. Kanda and M. Shibasaki

Use of Copper(I) Trifluoromethanesulfonate in $\beta$-Lactam Synthesis

J. Org. Chem., 54, 3511-3513 (1989)

90. M. Shibasaki, A. Takahashi, T. Aoki, H. Satoh and S. Narita

Synthesis of cis-Bicyclo[4.3.0]non-2-ene Derivatives. The Potent Homoisocarbacyclin Analogs Chem. Pharm. Bull., 37, 1647-1649 (1989)

91. M. Sodeoka and M. Shibasaki

Organic Synthesis Using Arene Tricarbony Chromium Complexes as a Catalyst

Organometallic News, 2, 2-5 (1989)

92. Y. Sato, M. Sodeoka and M. Shibasaki

Catalytic Asymmetric C-C Bond Formation: Asymmetric Synthesis of cis-Decalin Derivatives by Palladium-Catalyzed Cyclization of Prochiral Alkenyl Iodides

J. Org. Chem., 54, 4738-4739 (1989)

93. M. Mori, Y. Watanabe, K. Kagechika and M. Shibasaki

Ring Construction of Bicyclic $\gamma$-Lactams by Use of Electrochemical Oxidation

Heterocycles, 29, 2089-2092 (1989)

94. A. Takahashi, T. Yamamoto and M. Shibasaki

A Highly Stereoselective Synthesis of Methoxycarbonyl-Substituted Exocyclic Enol Ethers: A Synthesis of 5-Methoxycarbonylprostacyclin

Heterocycles, 30, 617-626 (1990)

95. H. Nakamura, K. Arata, T. Wakamatsu and M. Shibasaki

Alkylated Levoglucosan in Organic Synthesis. A Formal Total Synthesis of Elaiophylin

Chem. Pharm. Bull., 38, 2435-2441 (1990) 
96. S. Nakajima, K. Yoshida, M. Mori and Y. Ban and M. Shibasaki

Synthetic Approaches toward Mitomycins: Synthesis of the Decarbamoyloxymitomycin Derivative

J. Chem. Soc., Chem. Commun., 468-469 (1990)

97. N. Miyachi and M. Shibasaki

A Method for the Synthesis of Alkynyl Phenyl Sulfides from Alkynyltrimethylsilanes. A Novel Efficient Synthesis of the Thienamycin Intermediate from 3(R)-Hydroxybutyric Acid

J. Org. Chem., 55, 1975-1976 (1990)

98. M. Sodeoka, H. Yamada and M. Shibasaki

A New Method for the Stereocontrolled Synthesis of Silyl Dienol Ethers Using (Naphthalene)chromium Tricarbonyl Catalyzed Isomerization

J. Am. Chem. Soc., 112, 4906-4911 (1990)

99. Y. Sato, M. Sodeoka and M. Shibasaki

On the Role of Silver Salts in Asymmetric Heck-type Reaction. A Greatly Improved Catalytic Asymmetric Synthesis of cis-Decalin Derivatives

Chem. Lett., 1953-1954 (1990)

100. K. Iseki, T. Kaneyama, Y. Hayashi and M. Shibasaki

Synthesis of a New Chemically Stable Prostacyclin Analogue with High and Long-Lasting Activity

Chem. Pharm. Bull., 38, 1769-1771 (1990)

101. H. Sasai, Y. Kirio and M. Shibasaki

$\mathrm{Zr}(\mathrm{O}-t-\mathrm{Bu})_{4}$, an Efficient and Convenient Basic Reagent in Organic Synthesis. Utilization in Cross and Intramolecular Aldol Reaction

J. Org. Chem., 55, 5306-5308 (1990)

102. M. Mori, Y. Uozumi and M. Shibasaki

Incorporation of Molecular Nitrogen into Organic Compounds III. Reaction of Titanium-Nitrogen Complexes with Acid Halides and Acid Anhydrides

J. Organomet. Chem., 395, 255-267 (1990)

103. M. Mori, N. Uesaka and M. Shibasaki

Ring Construction by Zirconium-Promoted Reductive Coupling of Nitriles with Alkenes

J. Chem. Soc., Chem. Commun., 1222-1224 (1990)

104. Y. Uozumi, E. Mori, M. Mori and M. Shibasaki

Incorporation of Molecular Nitrogen into Organic Compounds IV. Novel Lactam Synthesis by Nitrogenation of Enol Lactones

J. Organomet. Chem., 399, 93-102 (1990)

105. M. Nishida, K. Iseki, M. Shibasaki and S. Ikegami

A Total Synthesis of (+)-Hirsutic Acid

Chem. Pharm. Bull., 38, 3230-3237 (1990)

106. M. Sodeoka, Y. Ogawa, Y. Kirio and M. Shibasaki

Stereocontrolled Synthesis of Exocyclic Olefins Using Arene Tricarbonyl Chromium Complex-Catalyzed Hydrogenation. I. Efficient Synthesis of Carbacyclin and Its Analogs

Chem. Pharm. Bull., 39, 309-322 (1991)

107. M. Sodeoka, T. Iimori and M. Shibasaki 
Stereocontrolled Synthesis of Exocyclic Olefins Using Arene Tricarbonyl Complex-Catalyzed Hydrogenation II. A Catalytic Asymmetric Synthesis of an Anthracycline Intermediate Chem. Pharm. Bull., 39, 323-327 (1991)

108. S. Satoh, M. Sodeoka, H. Sasai and M. Shibasaki

Control of Ring-Junction Stereochemistry via Radical Cyclization. A New Construction of trans-Hydrindans

J. Org. Chem., 56, 2278-2280 (1991)

109. Y. Uozumi, M. Mori and M. Shibasaki

New C-N-C Bond Formation Reaction using the Nitrogenation-Transmetallation Process

J. Chem. Soc., Chem. Commun., 81-83 (1991)

110. M. Mori, K. Kagechika, H. Sasai and M. Shibasaki

New Synthesis of 4-Acetoxy-2-azetizinones by Use of Electrochemical Oxidation

Tetrahedron, 47, 531-540 (1991)

111. M. Mori, N. Kaneta and M. Shibasaki

The Use of $\mathrm{R}_{3} \mathrm{SiSnR}_{3}$ in Organic Synthesis. A Novel Palladium-Catalyzed Tandem Transmetalation-Cyclization Reaction

J. Org. Chem., 56, 3486-3493 (1991)

112. K. Kagechika and M. Shibasaki

Asymmetric Heck Reaction: A Catalytic Asymmetric Synthesis of the Key Intermediate for $\Delta^{9(12)}$-Capnellene-3 $\beta, 8 \beta, 10 \alpha$-triol and $\Delta^{9(12)}$-Capnellene-3 $\beta, 8 \beta, 10 \alpha$,14-tetraol

J. Org. Chem., 56, 4093-4094 (1991)

113. H. Yamada, M. Sodeoka and M. Shibasaki

A New Method for the Stereocontrolled Synthesis of Dienamine Derivatives Using (Naphthalene)chromium Tricarbonyl Catalyzed Isomerization

J. Org. Chem., 56, 4569-4574 (1991)

114. M. Mori, N. Watanabe, N. Kaneta and M. Shibasaki

Synthesis of $E$-Vinylsilanes from Olefins with Vicinal Silyl and Stannyl Substituents

Chem. Lett., 1615-1618 (1991)

115. M. Mori, S. Nukui and M. Shibasaki

A Catalytic Asymmetric Synthesis of Cyclopentanoids via $\pi$-Allylpalladium Complexes

Chem. Lett., 1797-1800 (1991)

116. M. Mori, N. Kaneta, N. Isono and M. Shibasaki

Reaction of Metal Free $\mathrm{Bu}_{3} \mathrm{Sn}^{-}$Generated from $\mathrm{Bn}_{3} \mathrm{SnSiMe}_{3}-\mathrm{R}_{4} \mathrm{NX}$ with an Aryl or Vinyl Halide

Tetrahedron Lett., 32, 6139-6142 (1991)

117. N. Miyachi, H. Satoh and M. Shibasaki

The Binary Reagent PhSeSePh-CuOTf: a Useful Phenylselenylating Agent

J. Chem. Soc., Perkin Trans. 1, 2049-2050 (1991)

118. T. Suzuki, Y. Uozumi and M. Shibasaki

A Catalytic Asymmetric Synthesis of $\alpha$-Methylene Lactones by the Palladium-Catalyzed Carbonylation of Prochiral Alkenyl Halides

J. Chem. Soc., Chem. Commun., 1593-1595 (1991)

119. Y. Uozumi, M. Mori and M. Shibasaki 
New Organic Synthetic Methods Using Titanium-Nitrogen Complexes-Novel N1 Unit ReagentsJ. Synth. Org. Chem. Jpn., 49, 937-946 (1991)

120. K. Shigeno, K. Ohne, T. Yamaguchi, H. Sasai and M. Shibasaki

Synthetic Approaches to Phorbols via the Intramolecular Nitrile Oxide Cycloaddition: Stereocontrol of the B-C Ring Junction

Heterocycles, 33, 161-171 (1992)

121. K. Kawaguchi, S. Satoh, M. Mori and M. Shibasaki

Control of Ring-Junction Stereochemistry via Radical Cyclization. A New Construction of trans-Decalins

Chem. Lett., 395-398 (1992)

122. M. Shibasaki, Y. Sato and K. Kagechika

Catalytic Asymmetric Synthesis of Polycylic Compounds by Asymmetric Heck Reaction

J. Synth. Org. Chem. Jpn., 50, 826-837 (1992)

123. M. Shibasaki, A. Takahashi, T. Aoki, H. Sato, S. Yamada, M. Kudo, K. Kogi and S. Narita

A Novel Homoisocarbacyclin Analog with Potent and Long-Lasting Activity

Chem. Pharm. Bull., 40, 279-281 (1992)

124. Y. Sato, T. Honda and M. Shibasaki

A Catalytic Asymmetric Synthesis of Hydrindans

Tetrahedron Lett., 33, 2593-2596 (1992)

125. H. Sasai, T. Suzuki, S. Arai, T. Arai and M. Shibasaki

Basic Character of Rare Earth Metal Alkoxides. Utilization in Catalytic C-C Bond-Forming Reactions and Catalytic Asymmetric Nitroaldol Reactions

J. Am. Chem. Soc., 114, 4418-4420 (1992)

126. M. Mori, N. Uesaka and M. Shibasaki

Novel Synthesis of Nitrogen Heterocycles Using Zirconium-Promoted Reductive Coupling Formal Total Synthesis of Dendrobine

J. Org. Chem., 57, 3519-3521 (1992)

127. T. Takemoto, Y. Nishikimi, M. Sodeoka and M. Shibasaki

Synthesis of $c i s$-Decalin Derivative via $\pi$-Allylpalladium Intermediate and Its Transformation to Usefully Functionalized trans-Decalin Derivative

Tetrahedron Lett., 33, 3527-3530 (1992)

128. T. Takemoto, Y. Nishikimi, M. Sodeoka and M. Shibasaki

A Catalytic Asymmetric Synthesis of cis-Decalin Derivatives via $\pi$-Allylpalladium Intermediate Tetrahedron Lett., 33, 3531-3532 (1992)

129. M. Mori, Y. Uozumi and M. Shibasaki

New $\mathrm{C}-\mathrm{N}-\mathrm{C}$ Bond Formation Reaction Using Nitrogenation-Transmetallation Process Novel Ring Construction of Indole and Quinoline Derivatives

Heterocycles, 33, 819-830 (1992)

130. S. Narita, A. Takahashi, H. Sato, T. Aoki, S. Yamada and M. Shibasaki

An Improved Method for the Introduction of Carbon-Carbon Triple Bond at C-13 in PG Synthesis Tetrahedron Lett., 33, 4041-4044 (1992)

131. K. Shigeno, H. Sasai and M. Shibasaki 
Synthetic Studies towards Phorbols: A Stereocontrolled Synthesis of the Phorbol Skeleton in the Naturally Occurring Form

Tetrahedron Lett., 33, 4937-4940 (1992)

132. S. Narita, A. Takahashi, T. Aoki, H. Sato, S. Satoh, S. Yamada, M. Kudo, T. Yamaguchi, K. Kogi and M. Shibasaki

Syntheses and Biological Activities of Chemically Stable Prostacyclin Mimics with cis-Bicyclo[4.3.0]nonene Ring System: The Novel Homoisocarbacyclin Analogues

Bioorg. Med. Chem., 1, 77-118 (1993)

133. M. Mori, F. Saitoh, N. Uesaka and M. Shibasaki

Formal Total Synthesis of (-)-Dendrobine Using Zirconium Promoted Cyclization. Determination of the Absolute Configuration of the Intermediary Tricyclic Ketone

Chem. Lett., 213-216 (1993)

134. T. Takemoto, M. Sodeoka, H. Sasai and M. Shibasaki

Catalytic Asymmetric Synthesis of Benzylic Quaternary Carbon Centers. An Efficient Synthesis of (-)-Eptazocine

J. Am. Chem. Soc., 115, 8477-8478 (1993)

135. H. Sasai, T. Suzuki, N. Itoh, K. Tanaka, T. Date, K. Okamura and M. Shibasaki

Catalytic Asymmetric Nitroaldol Reaction Using Optically Active Rare Earth BINOL Complex: Investigation of the Catalyst Structure

J. Am. Chem. Soc., 115, 10372-10373 (1993)

136. M. Shibasaki and H. Sasai

Catalytic Asymmetric C-C Bond-Forming Reaction Using Optically Active Rare Earth Complex J. Synth. Org. Chem. Jpn., 51, 972-984 (1993)

137. M. Mori, A. Hashimoto and M. Shibasaki

Novel Synthesis of Heterocycles Using Stannyl Anion Generated from $\mathrm{Me}_{3} \mathrm{SiSnBu}_{3}$ and $\mathrm{F}^{-}$ J. Org. Chem., 58, 6503-6504 (1993)

138. S. Nukui, M. Sodeoka and M. Shibasaki

Catalytic Asymmetric Synthesis of a Functionalized Indolizidine Derivative. A Useful Intermediate Suitable for the Synthesis of Various Glycosidase Inhibitors

Tetrahedron Lett., 34, 4965-4968 (1993)

139. H. Sasai, T. Suzuki, N. Itoh, S. Arai and M. Shibasaki

Effect of Rare Earth Metals on the Catalytic Asymmetric Nitroaldol Reaction

Tetrahedron Lett., 34, 2657-2660 (1993)

140. T. Ohshima, M. Sodeoka and M. Shibasaki

Manganese(III)-Based Oxidative Free-Radical Reaction of $\alpha$-Allyl- $\beta$-keto Ester with Molecular Oxygen

Tetrahedron Lett., 34, 8509-8512 (1993)

141. M. Otsuka, H. Satake, Y. Sugiura, S. Murakami, S. Kobayashi and M. Shibasaki

Restructuring of the Bleomycin Metal Core. Novel Oxygen-Activating Ligands with Symmetrized Structure

Tetrahedron Lett., 34, 8497-8500 (1993)

142. S. Kobayashi, R. Tokunoh, R. Shinagawa, K. M. Murofushi and M. Shibasaki

Synthesis of 1-O-Acylglycerol 2,3-Cyclic Phosphate: Determination of the Absolute Structure of 
PHYLPA, A Specific Inhibitor of DNA Polymerase $\alpha$

Tetrahedron Lett., 34, 4047-4050 (1993)

143. M. Nakada, S. Kobayashi, S. Iwasaki, M. Ohno and M. Shibasaki

The First Total Synthesis of the Antitumor Macrolide, Rhizoxin

Tetrahedron Lett., 34, 1039-1042 (1993)

144. M. Sodeoka and M. Shibasaki

Arene Chromium Tricarbonyl Catalyzed Reactions in Organic Synthesis

Synthesis, 643-658 (1993)

145. K. Kondo, M. Sodeoka and M. Mori and M. Shibasaki

Asymmetric Heck Reaction: Catalytic Asymmetric Syntheses of Bicyclic Enones, Dienones and the Key Intermediate for Vernolepin

PERGAMON PRESS, 920-930 (1993)

146. K. Kondo, M. Sodeoka, M. Mori and M. Shibasaki

Asymmetric Heck Reaction. A Catalytic Asymmetric Synthesis of the Key Intermediate for Vernolepin

Tetrahedron Lett., 34, 4219-4222 (1993)

147. K. Kagechika, T. Ohshima and M. Shibasaki

Asymmetric Heck Reaction-Anion Capture Process. A Catalytic Asymmetric Synthesis of the Key Intermediates for the Capnellenols

Tetrahedron, 49, 1773-1782 (1993)

148. H. Sasai, T. Suzuki, N. Itoh and M. Shibasaki

Catalytic Asymmetric Nitroaldol Reactions. A New Practical Method for the Preparation of the Optically Active Lanthanum Complex

Tetrahedron Lett., 34, 851-854 (1993)

149. H. Sasai, N. Itoh, T. Suzuki and M. Shibasaki

Catalytic Asymmetric Nitroaldol Reaction: An Efficient Synthesis of (S)-Propranolol Using the Lanthanum Binaphthol Complex

Tetrahedron Lett., 34, 855-858 (1993)

150. M. Mori, N. Isono, N. Kaneta and M. Shibasaki

Novel Cyclization by Stannyl Anion Generated from $\mathrm{Me}_{3} \mathrm{SiSnBu}_{3}$ and $\mathrm{F}^{-}$. The Application to the Natural Product Synthesis

J. Org. Chem., 58, 2972-2976 (1993)

151. M. Shibasaki

Retrosynthetic Analysis

Chemistry Today, 38-42 (1993)

152. M. Mori, N. Kaneta, N. Isono, M. Shibasaki

Utilization of $\mathrm{Me}_{3} \mathrm{SiSnBu}_{3}$ in Organic-Synthesis. 1. Generation of a Stannyl Anion from $\mathrm{Me}_{3} \mathrm{SiSnBu}_{3}$ and $\mathrm{R}_{4} \mathrm{NX}$

J. Organomet. Chem., 455, 255-260 (1993)

153. M. Mori, N. Kaneta, M. Shibasaki

Utilization of $\mathrm{Bu}_{3} \mathrm{SnSiMe}_{3}$ in Organic-Synthesis. 2. New Cyclization by a Stannyl Anion Generated from $\mathrm{Bu}_{3} \mathrm{SnSiMe}_{3}$ and $\mathrm{R}_{4} \mathrm{NX}$

J. Organomet. Chem., 464, 35-40 (1993) 
154. K. Sugita, K. Shigeno, C. F. Neville, H. Sasai and M. Shibasaki

Synthetic Studies towards Phorbols: Synthesis of B or C Ring Substituted Phorbol Skeletons in the Naturally Occurring Form

Synlett, 325-330 (1994)

155. H. Sasai, T. Arai and M. Shibasaki

Catalytic Asymmetric Michael Reactions Promoted by a Lithium-Free Lanthanum-BINOL Complex

J. Am. Chem. Soc., 116, 1571-1572 (1994)

156. H. Sasai, S. Arai and M. Shibasaki

Catalytic Aldol Reaction with Sm(HMDS) $)_{3}$ and Its Application for the Introduction of a CarbonCarbon Triple Bond at C-13 in Prostaglandin Synthesis

J. Org. Chem., 59, 2661-2664 (1994)

157. Y. Sato, S. Nukui, M. Sodeoka and M. Shibasaki

Asymmetric Heck Reaction of Alkenyl Iodides in the Presence of Silver Salts. Catalytic Asymmetric Synthesis of Decalin and Functionalize Indolizidine Derivatives

Tetrahedron, 50, 371-382 (1994)

158. M. Sodeoka, H. Yamada, T. Shimizu, S. Watanuki and M. Shibasaki

Carbon-Carbon Bond-Forming Reaction through a $\eta^{5}$-Pentadienylchromium Complex

J. Org. Chem., 59, 712-714 (1994)

159. Y. Kurihara, M. Sodeoka and M. Shibasaki

Asymmetric Heck-type Reaction Utilizing Hypervalent Alkenyliodonium Salt

Chem. Pharm. Bull., 42, 2357-2359 (1994)

160. S. Nakamura and M. Shibasaki

Synthetic Studies on Tautomycin. Stereoselective Construction of the $\mathrm{C}_{1}-\mathrm{C}_{26}$ Region

Tetrahedron Lett., 35, 4145-4148 (1994)

161. H. Sasai, W.-S. Kim, T. Suzuki, M. Shibasaki, M. Mitsuda, J. Hasegawa and T. Ohashi

Diastereoselective Catalytic Asymmetric Nitroaldol Reaction Utilizing Rare Earth-Li- $(R)$-BINOL

Complex. A Highly Efficient Synthesis of Norstatin

Tetrahedron Lett., 35, 6123-6126 (1994)

162. Y. Koga, M. Sodeoka and M. Shibasaki

Palladium-Catalyzed Asymmetric Arylation of 4,7-Dihydro-1,3-dioxepin. Catalytic Asymmetric Synthesis of $\gamma$-Butyrolactone Derivatives

Tetrahedron Lett., 35, 1227-1230 (1994)

163. H. Sasai, Y. M. A. Yamada, T. Suzuki and M. Shibasaki

Syntheses of $(S)-(-)$-Pindolol and $\left[3^{\prime}-{ }^{13} \mathrm{C}\right]-(R)-(-)-P i n d o l o l$ Utilizing a Lanthanum-Lithium$(R)$-BINOL $((R)$-LLB) Catalyzed Nitroaldol Reaction

Tetrahedron, 50, 12313-12318 (1994)

164. T. Sugiyama, M. Ohno, M. Shibasaki, M. Otsuka, Y. Sugiura, S. Kobayashi and K. Maeda On The Mechanism of Enzymatic Inactivation of Bleomycin. The $\beta$-Aminoalaninamide Moiety as an Enzyme-Dependent Molecular Switch

Bioorg. Med. Chem. Lett., 4, 705-710 (1994)

165. T. Sugiyama, M. Ohno, M. Otsuka, M. Shibasaki, Y. Sugiura, S. Kobayashi and K. Maeda Transition-Metal Binding Site of Bleomycin. Significance of the $\beta$-Aminoalaninamide Appendage 
in Regulating Oxygen Activation

Heterocycles, 37, 275-282 (1994)

166. N. Uesaka, F. Saitoh, M. Mori, M. Shibasaki, K. Okamura and T. Date

Formal Total Synthesis of (-)-Dendrobine Using Zirconium-Promoted Reductive Cyclization J. Org. Chem., 59, 5633-5642 (1994)

167. N. Uesaka, F. Saitoh, M. Mori and M. Shibasaki

Novel Synthsis of Nitrogen Heterocycles Using Zirconium-Promoted Reductive Cyclization J. Org. Chem., 59, 5643-5649 (1994)

168. Y. Ban, S. Nakajima K. Yoshida, M. Mori and M. Shibasaki

Synthetic Approaches toward Mitomycins: Synthesis of the Decarbamoyloxymitomycin Derivative

Heterocycles, 39, 657-667 (1994)

169. K. Ohrai, K. Kondo, M. Sodeoka and M. Shibasaki

Effects of Solvents and Additives in the Asymmetric Heck Reaction of Alkenyl Triflates: Catalytic Asymmetric Synthesis of Decalin Derivatives and Determination of the Absolute Stereochemistry of (+)-Vernolepin

J. Am. Chem. Soc., 116, 11737-11748 (1994)

170. M. Shibasaki and M. Sodeoka

Asymmetric Heck Reaction: Catalytic Asymmetric Syntheses of Bioactive Molecules

J. Synth. Org. Chem. Jpn., 52, 956-967 (1994)

171. M. Shibasaki

Catalytic Asymmetric Synthesis Using Rare Earth Metals

Farumashia, 30, 1273-1275 (1994)

172. H. Sasai, T. Arai and E. Emori and M. Shibasaki

Efficient Synthesis of $\mathrm{C}_{10}$ Chiron by Lewis Acid Catalyzed Rearrangement of $(+)-\alpha-3,4-E p o x y c a r a n e$

J. Org. Chem., 60, 465-467 (1995)

173. S. Hosono, W.-S. Kim, H. Sasai and M. Shibasaki

A New Glycosylation Procedure Utilizing Rare Earth Salts and Glycosyl Fluorides, with or without the Requirement of Lewis Acids

J. Org. Chem., 60, 4-5 (1995)

174. K. Sugita, C. F. Neville, M. Sodeoka, H. Sasai and M. Shibasaki

Stereocontrolled Syntheses of Phorbol Analogs and Evaluation of Their Binding Affinity to PKC Tetrahedron Lett., 36, 1067-1070 (1995)

175. S. Nukui, M. Sodeoka, H. Sasai and M. Shibasaki

Regio- and Stereoselective Functionalization of an Optically Active Tetrahydroindolizine Derivative. Catalytic Asymmetric Syntheses of Lentiginosine, 1,2-Diepilentiginosine, and Gephyrotoxin 209D

J. Org. Chem., 60, 398-404 (1995)

176. Y. Yoshizaki, H. Satoh, Y. Sato, S. Nukui, M. Mori and M. Shibasaki

Palladium-Mediated Asymmetric Synthesis of cis-3,6-Disubstituted Cyclohexenes. A Short Total Synthesis of Optically Active (+)- $\gamma$-Lycorane

J. Org. Chem., 60, 2016-2021 (1995) 
177. K. Uotsu, H. Sasai and M. Shibasaki

Preparation of a New Asymmetric Lanthanoid Complex Catalyst for the Mukaiyama Aldol Reaction

Tetrahedron: Asymmetry, 6, 71-74 (1995)

178. Y. Sato, M. Mori and M. Shibasaki

Asymmetric Heck Reaction: A Catalytic Asymmetric Synthesis of the Key Intermediate of (-)-Oppositol and (-)-Prepinnaterpene

Tetrahedron: Asymmetry, 6, 757-766 (1995)

179. M. Sodeoka, K. Ohrai and M. Shibasaki

Catalytic Asymmetric Aldol Reaction via Chiral Pd(II) Enolate in Wet DMF

J. Org. Chem., 60, 2648-2649 (1995)

180. H. Sasai, T. Arai, Y. Satow, K. N. Houk and M. Shibasaki

The First Heterobimetallic Multifunctional Asymmetric Catalyst

J. Am. Chem. Soc., 117, 6194-6198 (1995)

181. K. Kondo, M. Sodeoka and M. Shibasaki

Regioselective Olefin Insertion in Asymmetric Heck Reaction. Catalytic Asymmetric Synthesis of a Versatile Intermediate for Diterpene Syntheses

J. Org. Chem., 60, 4322-4323 (1995)

182. T. Suzuki, N. Itoh, H. Sasai and M. Shibasaki

Catalytic Asymmetric Synthesis of Propranolol and Metoprolol Using La-Li-BINOL Complex

Appl. Organomet. Chem., 9, 421-426 (1995)

183. M. Shibasaki, H. Sasai and T. Arai

Catalytic Asymmetric Carbon-Carbon Bond-Forming Reaction Utilizing Rare Earth Metal Complexes

Pure Appl. Chem., 6, 105-112 (1995)

184. W.-S. Kim, S. Hosono, H. Sasai and M. Shibasaki

Rare Earth Perchlorate Catalyzed Glycosidation of Glycosyl Fluorides with Trimethylsilyl Ethers Tetrahedron Lett., 36, 4443-4446 (1995)

185. H. Sasai, S. Arai, Y. Tahara and M. Shibsasaki

Catalytic Asymmetric Synthesis of $\alpha$-Amino Phosphonates Using Lanthanoid-Potassium-BINOL Complexes

J. Org. Chem., 60, 6656-6657 (1995)

186. H. Takahashi, M. Yoshioka, M. Shibasaki, M. Ohno, N. Imai and S. Kobayashi

A Catalytic Enantioselective Reaction Using a $C_{2}$-Symmetric Disulfonamide as a Chiral Ligand: Simmons-Smith Cyclopropanation of Allylic Alcohols by the $\mathrm{Et}_{2} \mathrm{Zn}_{-}-\mathrm{CH}_{2} \mathrm{I}_{2}-$ Disulfonamide System Tetrahedron, 51, 12013-12026 (1995)

187. H. Kurosu, O. Hazeki, I. Kukimoto, S. Honzawa, M. Shibasaki, M. Nakada, M. Ui and T. Takada Radiolabeling of Catalytic Subunits of PI 3-Kinases with 17 $\beta$-Hydroxy-16 $\alpha$-[125I]iodowortmannin: Identification of the $G \beta \gamma$-Sensitive Isoform as a Complex Composed of 46-kDa and 100-kDa Subunits Biochem. Biophys. Res. Commun., 216, 655-661 (1995)

188. R. Tokunoh, M. Sodeoka, K. Aoe and M. Shibasaki Synthesis and Crystal Structure of a New $\mathrm{C}_{2}$-Symmetric Chiral Bis-Sulfoxide Ligand and Its 
Palladium(II) Complex

Tetrahedron Lett., 36, 8035-8038 (1995)

189. H. Sasai, T. Tokunaga, S. Watanabe, T. Suzuki, N. Itoh and M. Shibasaki

Efficient Diastereoselective and Enantioselective Nitroaldol Reactions from Prochiral Starting Materials: Utilization of La-Li-6,6'-Disubstituted BINOL Complexes as Asymmetric Catalysts J. Org. Chem., 60, 7388-7389 (1995)

190. K. Kondo, M. Sodeoka and M. Shibasaki

Catalytic Asymmetric Synthesis of a Versatile Intermediate for Diterpene Syntheses. Regioselective Olefin Insertion in Asymmetric Heck Reactions

Tetrahedron: Asymmetry, 6, 2453-2464 (1995)

191. S. Honzawa, M. Nakada, H. Kurosu, O. Hazeki, T. Katada and M. Shibasaki

$17 \beta$-Hydroxy-16 $\alpha-\left[{ }^{125}\right.$ I]Iodowortmannin, A Sensitive Labeling Agent for PI 3-Kinases

Chem. Pharm. Bull., 43, 2276-2278 (1995)

192. M. Sodeoka, K. Uotsu and M. Shibasaki

Photoaffinity Labeling of PKC with a Phorbol Derivative: Importance of the 13-Acyl Group in Phorbol Ester-PKC Interaction

Tetrahedron Lett., 36, 8795-8798 (1995)

193. W.-S. Kim, S. Hosono, H. Sasai and M. Shibasaki

Rare Earth Salts Promoted Glycosidation of Glycosyl Fluorides

Heterocycles, 42, 795-809 (1996)

194. J.-P. Dai, M. Sodeoka and M. Shibasaki

Determination of the C-7,9,12,13,17 and 18 Stereochemistries of Tautomycetin. Synthesis of the Tautomycetin Degradation Product

Tetrahedron Lett., 37, 491-494 (1996)

195. T. Arai, M. Bougauchi, H. Sasai and M. Shibasaki

Catalytic Asymmetric Synthesis of $\alpha$-Hydroxy Phosphonates Using the Al-Li-BINOL Complex J. Org. Chem., 61, 2926-2927 (1996)

196. K. Sugita, D. Sawada, M. Sodeoka, H. Sasai and M. Shibasaki

Novel Phorbol Analogs which Bind to Protein Kinase C (PKC) without Activation

Chem. Pharm. Bull., 44, 463-465 (1996)

197. T. Arai, H. Sasai, K. Aoe, K. Okamura, T. Date and M. Shibasaki

A New Multifunctional Heterobimetallic Asymmetric Catalyst for Michael Additions and Tandem Michael-Aldol Reactions

Angew. Chem., Int. Ed. Engl., 35, 104-106 (1996)

198. R. Tokunoh, H. Tomiyama, M. Sodeoka and M. Shibasaki

Catalytic Asymmetric Intramolecular Cyclopropanation of Enol Silyl Ether. Synthesis of the Phorbol CD-Ring Skeleton

Tetrahedron Lett., 37, 2449-2452 (1996)

199. M. Shibasaki and H. Sasai

Catalytic Asymmetric Carbon-Carbon Bond-Forming Reaction Utilizing Rare Earth Metal Complexes

Pure Appl. Chem., 68, 523-530 (1996) 
200. M. Shibasaki

New Catalytic Asymmetric Carbon-Carbon Bond-Forming Reactions

Adv. Metal-Org. Chem., 5, 119-151 (1996)

201. H. Sasai, E. Emori, T. Arai and M. Shibasaki

Catalytic Asymmetric Michael Reactions Promoted by the La-Na-BINOL Complex (LSB). Enantioface Selection on Michael Donors

Tetrahedron Lett., 37, 5561-5564 (1996)

202. A. Kojima, T. Takemoto, M. Sodeoka and M. Shibasaki

Catalytic Asymmetric Synthesis of Halenaquinone and Halenaquinol

J. Org. Chem., 61, 4876-4877 (1996)

203. T. Ohshima, K. Kagechika M. Adachi, M. Sodeoka and M. Shibasaki

Asymmetric Heck Reaction-Carbanion Capture Process. Catalytic Asymmetric Total Synthesis of $(-)-\Delta^{9(12)}-$ Capnellene

J. Am. Chem. Soc., 118, 7108-7116 (1996)

204. S. Sato, M. Nakada and M. Shibasaki

The First Chemical Synthesis of Wortmannin by Starting from Hydrocortisone

Tetrahedron Lett., 37, 6141-6144 (1996)

205. S. Shimizu, S. Nakamura, M. Nakada and M. Shibasaki

Total Synthesis of (+)-Tautomycin

Tetrahedron, 52, 13363-13408 (1996)

206. T. Arai, Y. M. A. Yamada, N. Yamamoto, H. Sasai and M. Shibasaki

Self-Assembly of Heterobimetallic Complexes and Reactive Nucleophiles: A General Strategy for the Activation of Asymmetric Reactions Promoted by Heterobimetallic Catalysis

Chem. Eur. J., 2, 1368-1372 (1996)

207. W.-S. Kim, H. Sasai and M. Shibasaki

$\beta$-Selective Glycosylation with $\alpha$-Mannosyl Fluorides Using Tin(II) Triflate and Lanthanum Perchlorate

Tetrahedron Lett., 37, 7797-7800 (1996)

208. K. Iseki, S. Oishi, H. Sasai and M. Shibasaki

Catalytic Asymmetric Nitroaldol Reaction of $\alpha, \alpha$-Difluoro Aldehydes Mediated by Rare Earth-Lithium-BINOL Complexes

Tetrahedron Lett., 37, 9081-9084 (1996)

209. M. Otsuka, H. Satake, S. Murakami, M. Doi, T. Ishida, M. Shibasaki and Y. Sugiura

An Artificial $\mathrm{Cu}^{\text {II }}$ Complex with Intriguing Oxygen Radical-Quenching Profile. X-Ray Structure, Cytochrome c Assay, and ESR Study

Bioorg. Med. Chem., 4, 1703-1708 (1996)

210. H. Gröger, Y. Saida, S. Arai, J. Martens, H. Sasai and M. Shibasaki

First Catalytic Asymmetric Hydrophosphonylation of Cyclic Imines: Highly Efficient Enantioselective Approach to a 4-Thiazolidinylphosphonate via Chiral Titanium and Lanthanoid Catalysis

Tetrahedron Lett., 37, 9291-9292 (1996)

211. M. Sodeoka, R. Tokunoh, F. Miyazaki, E. Hagiwara and M. Shibasaki

Stable Diaqua Palladium(II) Complexes of BINAP and Tol-BINAP as Highly Efficient Catalysts 
for Asymmetric Aldol Reactions

Synlett, 463-466 (1997)

212. H. Sasai, S. Watanabe and M. Shibasaki

A New Practical Preparation Method for Lanthanum-Lithium-Binaphtol Catalysts (LLBs) for Use in Asymmetric Nitroaldol Reactions

Enantiomer, 2, 267-271 (1997)

213. M. Shibasaki, H. Sasai and T. Arai

Catalytic Asymmetric Carbon-Carbon Bond-Forming Reaction Utilizing Rare Earth Metal Complexes

Medicinal Chemistry: Today and Tomorrow, 105-112 (1997)

214. M. Bougauchi, S. Watanabe, T. Arai, H. Sasai and M. Shibasaki

Catalytic Asymmetric Epoxidation of $\alpha, \beta$-Unsaturated Ketones Promoted by Lanthanoid Complexes

J. Am. Chem. Soc., 119, 2329-2330 (1997)

215. M. Shibasaki and H. Sasai

Development of Asymmetric Catalysts with Enzyme-like Functions

Chemistry Today, 33-38 (1997)

216. H. Sasai, M. Bougauchi, T. Arai and M. Shibasaki

Enantioselective Synthesis of $\alpha$-Hydroxy Phosphonates Using the $\mathrm{LaLi}_{3}$ tris(binaphthoxide) Catalyst (LLB), Prepared by an Improved Method

Tetrahedron Lett., 38, 2717-2720 (1997)

217. M. Shibasaki, C. D. J. Boden and A. Kojima

The Asymmetric Heck Reaction

Tetrahedron, 53, 7371-7395 (1997)

218. Y. Kobayashi, T. Arie, M. Shibasaki and I. Yamaguchi

4-Allyl-2-azetidinone and Penicillium simplicissimum Cooperate to Control Solilborne Fusarium

Diseases

J. Pesticide Sci., 22, 113-118 (1997)

219. T. Iida, N. Yamamoto, H. Sasai and M. Shibasaki

New Asymmetric Reactions Using a Gallium Complex: A Highly Enantioselective Ring Opening of Epoxides with Thiols Catalyzed by a Gallium $\bullet$ Lithium•Bis(binaphthoxide) Complex

J. Am. Chem. Soc., 119, 4783-4784 (1997)

220. M. Shibasaki, H. Sasai and T. Arai

Asymmetric Catalysis with Heterobimetallic Compounds

Angew. Chem., Int. Ed. Engl., 36, 1236-1256 (1997)

221. A. Kojima, S. Honzawa, C. D. J. Boden and M. Shibasaki

Tandem Suzuki Cross-coupling-Heck Reactions

Tetrahedron Lett., 38, 3455-3458 (1997)

222. A. Kojima, C. D. J. Boden and M. Shibasaki

Synthesis and Evaluation of a New Chiral Arsine Ligand; 2,2'-Bis(diphenylarsino)-1,1'-binaphthyl (BINAs)

Tetrahedron Lett., 38, 3459-3460 (1997) 
223. Y. M. A. Yamada, N. Yoshikawa, H. Sasai and M. Shibasaki

Direct Catalytic Asymmetric Aldol Reactions of Aldehydes and Unmodified Ketones Angew. Chem., Int. Ed. Engl., 36, 1871-1873 (1997)

224. H. Sasai, M. Hiroi, Y. M. A. Yamada and M. Shibasaki

The First Tandem Inter-intramolecular Catalytic Asymmetric Nitroaldol Reaction Utilizing a $\mathrm{LnLi}_{3}$ tris $((R)$-binaphthoxide) Complex $((R)$-LnLB) (Ln: Lanthanoid)

Tetrahedron Lett., 38, 6031-6034 (1997)

225. R. Göttlich, K. Yamakoshi, H. Sasai and M. Shibasaki

A New and Selective Metal-Catalyzed Baeyer-Villiger Oxidation Procedure

Synlett, 971-973 (1997)

226. E. Takaoka, N. Yoshikawa, Y. M. A. Yamada, H. Sasai and M. Shibasaki

Catalytic Asymmetric Synthesis of Arbutamine

Heterocycles, 46, 157-163 (1997)

227. K. Iseki, S. Oishi, H. Sasai and M. Shibasaki

Synthesis and Biological Evaluation of a Fluorinated Analog of the $\beta$-Adrenergic Blocking Agent, Metoprolol

Bioorg. Med. Chem. Lett., 7, 1273-1274 (1997)

228. T. Oshitari, M. Shibasaki, T. Toshizawa, M. Tomita, K. Takao and S. Kobayashi

Synthesis of 2-O-(3-O-Carbamoyl- $\alpha$-D-mannopyranosyl)-L-gulopyranose: Sugar Moiety of Antitunor Antibiotic Bleomycin

Tetrahedron, 53, 10993-11006 (1997)

229. T. Arai, H. Sasai, K. Yamaguchi and M. Shibasaki

Regioselective Catalytic Asymmetric Reaction of Horner-Wadsworth-Emmons Reagent with Enones: The Odyssey of Chiral Aluminum Catalysts

J. Am. Chem. Soc., 120, 441-442 (1998)

230. M. Sodeoka, M. A. Arai, K. Adachi, K. Uotsu and M. Shibasaki

Rational Design, Synthesis, and Evaluation of a New Type of PKC Inhibitor

J. Am. Chem. Soc., 120, 457-458 (1998)

231. S. Y. Cho and M. Shibasaki

Synthesis and Evaluation of a New Chiral Ligand:

2-Diphenylarsino-2'-diphenylphosphino-1,1'-binaphthyl (BINAPAs)

Tetahetron Lett., 39, 1773-1776 (1998)

232. A. Kojima, T. Takemoto, M. Sodeoka and M. Shibasaki

Catalytic Asymmetric Synthesis of Halenaquinone and Halenaquinol

Synthesis, 581-589 (1998)

233. H. Gröger, Y. Saida, H. Sasai, K. Yamaguchi, J. Martens and M. Shibasaki

A New and Highly Efficient Asymmetric Route to Cyclic $\alpha$-Amino Phosphonates: The First Catalytic Enantioselective Hydrophosphonylation of Cyclic Imines Catalyzed by Chiral Heterobimetallic Lanthanoid Complexes

J. Am. Chem. Soc., 120, 3089-3103 (1998)

234. M. Shibasaki, T. Iida Y. M. A. Yamada

Development of Multifunctional Asymmetric Catalysts and Their Application to Practical Organic Synthesis 
J. Synth. Org. Chem. Jpn., 56, 344-356 (1998)

235. T. Morita, T. Arai, H. Sasai and M. Shibasaki

Utilization of Heterobimetallic Complexes as Lewis Acids

Tetrahedron: Asymmetry, 9, 1445-1450 (1998)

236. M. Sodeoka and M. Shibasaki

Asymmetric Synthesis Using Palladium Catalysts

Pure Appl. Chem., 70, 411-414 (1998)

237. K. Yamada, T. Arai, H. Sasai and M. Shibasaki

A Catalytic Asymmetric Synthesis of 11-Deoxy-PGF $1^{a}$ Using ALB, a Heterobimetallic Multifunctional Asymmetric Complex

J. Org. Chem., 63, 3666-3672 (1998)

238. Y. M. A. Yamada and M. Shibasaki

Direct Catalytic Asymmetric Aldol Reactions Promoted by a Novel Barium Complex

Tetrahedron Lett., 39, 5561-5564 (1998)

239. M. Shibasaki, H. Sasai, T. Arai and T. Iida

Heterobimetallic Asymmetric Catalysts. Developments and Applications

Pure Appl. Chem., 70, 1027-1034 (1998)

240. M. Shibasaki and K. Uotsu

PKC Activations and Inhibitors

IGAKUSHOIN, 49, 290-295 (1998)

241. K. Uotsu, M. Sodeoka and M. Shibasaki

Photoaffinity Labeling of PKC Isozymes by Phorbol Ester Derivatives

Bioorg. Med.Chem., 6, 1117-1126 (1998)

242. H. Gröger, E. M. Vogl and M. Shibasaki

New Catalytic Concepts for the Asymmetric Aldol Reaction

Chem. Eur. J., 4, 1137-1141 (1998)

243. T. Iida, N. Yamamoto, H.-G. Woo and M. Shibasaki

Enantioselective Ring Opening of Epoxides with 4-Methoxyphenol Catalyzed by Gallium Heterobimetallic Complexes: An Efficient Method for the Synthesis of Optically Active 1,2-Diol Monoethers

Angew. Chem. Int. Ed., 37, 2223-2226 (1998)

244. E. M. Vogl, S. Matsunaga, M. Kanai, T. Iida and M. Shibasaki

Linking BINOL: $\mathrm{C}_{2}$-Symmetric Ligands for Investigations on Asymmetric Catalysis

Tetrahedron Lett., 39, 7917-7920 (1998)

245. F. Miyazaki, K. Uotsu, and M. Shibasaki

Silver Salt Effects on an Asymmetric Heck Reaction. Catalytic Asymmetric Total Synthesis of $(+)$-Xestoquinone

Tetrahedron, 54, 13073-13078 (1998)

246. S. Shimizu, K. Ohori, T. Arai, H. Sasai and M. Shibasaki

A Catalytic Asymmetric Synthesis of Tubifolidine

J. Org. Chem., 63, 7547-7551 (1998) 
247. K. Funabashi, Y. Saida, M. Kanai, T. Arai, H. Sasai and M. Shibasaki

Catalytic Asymmetric Michael Addition of Nitromethane to Enones Controlled by $(R)$-LPB

Tetrahedron Lett., 39, 7557-7558 (1998)

248. S. Watanabe, Y. Kobayashi, T. Arai, H. Sasai, M. Bougauchi and M. Shibasaki

Water vs. Desiccant. Improvement of Yb-BINOL Complex Catalyzed Enantioselective Epoxidation of Enones

Tetrahedron Lett., 39, 7353-7356 (1998)

249. M. Shibasaki, A. Kojima and S. Shimizu

Catalytic Asymmetric Synthesis of Natural Products with Heterocyclic Rings

J. Heterocycl. Chem., 35, 1057-1064 (1998)

250. S. Watanabe, T. Arai, H. Sasai, M. Bougauchi and M. Shibasaki

The First Catalytic Enatioselective Synthesis of cis-Epoxyketones from cis-Enones

J. Org. Chem., 63, 8090-8091 (1998)

251. S. Y. Cho and M. Shibasaki

The Asymmetric Synthesis of Cyclopentane Derivatives by Palladium-Catalyzed Coupling of Prochiral Alkylboron Compounds

Tetrahedron: Asymmetry, 9, 3751-3754 (1998)

252. S. Yamasaki, T. Iida and M. Shibasaki

Direct Catalytic Asymmetric Mannich-type Reaction of Unmodified Ketones Utilizing the Cooperation of an AlLibis(binaphthoxide) Complex and $\mathrm{La}(\mathrm{OTf})_{3} \bullet \mathrm{nH}_{2} \mathrm{O}$

Tetrahedron Lett., 40, 307-310 (1999)

253. S. Honzawa, T. Mizutani and M. Shibasaki

Synthetic Studies on (+)-Wortmannin. An Asymmetric Construction of an Allylic Quaternary Carbon Center by a Heck Reaction

Tetrahedron Lett., 40, 311-314 (1999)

254. K. Yamakoshi, S. Harwood, M. Kanai and M. Shibasaki

Catalytic Asymmetric Addition of Diphenylphosphine Oxide to Cyclic Imines

Tetrahedron Lett., 40, 2565-2568 (1999)

255. Y. Hamashima, D. Sawada, M. Kanai and M. Shibasaki

A New Bifunctional Asymmetric Catalysis: An Efficient Catalytic Asymmetric Cyanosilylation of Aldehydes

J. Am. Chem. Soc., 121, 2641-2642 (1999)

256. N. Yoshikawa, Y. M. A. Yamada, J. Das, H. Sasai and M. Shibasaki

Direct Catalytic Asymmetric Aldol Reaction

J. Am. Chem. Soc., 121, 4168-4178 (1999)

257. H. Sato, Y. S. Kim and M. Shibasaki

A Catalytic Asymmetric Synthesis of a Versatile Intermediate for Phorbol Derivatives

Tetrahedron Lett., 40, 2973-2976 (1999)

258. M. Shibasaki and E. M. Vogl

The Palladium-Catalyzed Arylation and Vinylation of Alkenes- Enantioselective Fashion

J. Organomet. Chem., 576, 1-15 (1999)

259. M. Kanai, Y. Hamashima and M. Shibasaki 
Design and Development of Lewis Acid-Lewis Base Bifunctional Asymmetric Catalyst Farumashia, 35, 690-694 (1999)

260. E. Emori, T. Iida, and M. Shibasaki

Catalytic Kinetic Resolution Reaction of ( \pm )-5-Methylbicyclo[3.3.0]-oct-1-ene-3,6-dione J. Org. Chem., 64, 5318-5320 (1999)

261. S. Yamasaki, T. Iida and M. Shibasaki

Direct Catalytic Asymmetric Mannich Reaction of Unmodified Ketones: Cooperative Catalysis of an AlLibis(binaphthoxide) Complex and $\mathrm{La}(\mathrm{OTf})_{3} \cdot \mathrm{nH}_{2} \mathrm{O}$

Tetrahedron, 55, 8857-8867 (1999)

262. E. M. Vogl, H. Gröger and M. Shibasaki

Towards Perfect Asymmetric Catalysis: Additives and Cocatalysts

Angew. Chem. Int. Ed., 38, 1570-1577 (1999)

263. F. Miyazaki, K. Yamaguchi and M. Shibasaki

The Synthesis of a New Palladacycle Catalyst. Development of a High Performance Catalyst for Heck Reactions

Tetrahedron Lett., 40, 7379-7383 (1999)

264. K. Yamada, S. J. Harwood, H. Gröger, and M. Shibasaki

The First Catalytic Asymmetric Nitro-Mannich-Type Reaction Promoted by a New Heterobimetallic Complex

Angew. Chem. Int. Ed., 38, 3504-3506 (1999)

265. M. Shibasaki

Multifunctional Asymmetric Catalysis

Chemtracts, Org. Chem., 12, 979-988 (1999)

266. M. Shibasaki

Multifunctional Asymmetric Catalysis

Enantiomer, 4, 513-527 (1999)

267. M. Shibasaki

Phorbols: Chemical Synthesis and Chemical Biology

YAKUGAKU ZASSHI, 120, 76-90 (2000)

268. A. Sekine, N. Kumagai, K. Uotsu, T. Ohshima and M. Shibasaki

An Efficient Method for the Synthesis of Versatile Intermediates Leading to 13-Deoxy- and 9,13-Dideoxyphorbols

Tetrahedron Lett., 41, 509-513 (2000)

269. I. Sakurada, S. Yamasaki, R. Göttlich, T. Iida, M. Kanai, and M. Shibasaki

Direct Chlorohydrin and Acetoxy Alcohol Synthesis from Olefins Promoted by a Lewis Acid, Bis(trimethylsilyl) Peroxide and $\left(\mathrm{CH}_{3}\right)_{3} \mathrm{SiX}$

J. Am. Chem. Soc., 122, 1245-1246 (2000)

270. D. Sawada and M. Shibasaki

Enantioselective Total Synthesis of Epothilone A Using Multifunctional Asymmetric Catalysis Angew. Chem. Int. Ed., 39, 209-213 (2000)

271. S. Matsunaga, J. Das, J. Roels, E. M. Vogl, N. Yamamoto, T. Iida, K. Yamaguchi and M. Shibasaki 
Catalytic Enantioselective meso-Epoxide Ring Opening Reaction with Phenolic Oxygen Nucleophile Promoted by Gallium Heterobimetallic Multifunctional Complexes

J. Am. Chem. Soc., 122, 2252-2260 (2000)

272. I. Sakurada, S. Yamasaki, M. Kanai and M. Shibasaki

Dichlorotin Oxide-Catalyzed New Direct Functionalization of Olefins: Synthesis of trans $\beta$-Azidohydrins and 1,2-Diols

Tetrahedron Lett., 41, 2415-2418 (2000)

273. M. Kanai, Y. Hamashima and M. Shibasaki

Design of a New Bifunctional Asymmetric Catalyst from Carbohydrates: Application to Catalytic Asymmetric Cyanosilylation of Aldehydes and Acetophenone

Tetrahedron Lett., 41, 2405-2409 (2000)

274. M. Takamura, Y. Hamashima, H. Usuda, M. Kanai and M. Shibasaki

A Catalytic Asymmetric Strecker-type Reaction: Interesting Reactivity Difference between TMSCN and HCN

Angew. Chem. Int. Ed., 39, 1650-1652 (2000)

275. Y. S. Kim, S. Matsunaga, J. Das, A. Sekine, T. Ohshima and M. Shibasaki

Stable, Storable and Reusable Asymmetric Catalyst: a Novel La-linked-BINOL Complex for Catalytic Asymmetric Michael Reaction

J. Am. Chem. Soc., 122, 6506-6507 (2000)

276. K. Ohori, S. Shimizu, T. Ohshima and M. Shibasaki

Catalytic Asymmetric Synthesis of 19,20-Dihydroakuammicine

Chirality, 12, 401-403 (2000)

277. M. Takamura, K. Funabashi, M. Kanai and M. Shibasaki

Asymmetric Reissert-type Reaction Promoted by Bifunctional Catalyst

J. Am. Chem. Soc., 122, 6327-6328 (2000)

278. I. Schlemminger, Y. Saida, H. Gröger, W. Maison, N. Durot, H. Sasai, M. Shibasaki and J. Martens

Concept of Improved Rigidity: How to Make Enantioselective Hydrophosphonylation of Cyclic Imines Catalyzed by Chiral Heterobimetallic Lanthanoid Complexes Almost Perfect

J. Org. Chem., 65, 4818-4825 (2000)

279. Y. Hamashima, M. Kanai and M. Shibasaki

Catalytic Enantioselective Cyanosilylation of Ketones

J. Am. Chem. Soc., 122, 7412-7413 (2000)

280. D. Sawada, M. Kanai and M. Shibasaki

Enantioselective Total Synthesis of Epothilone A and B Using Multifunctional Asymmetric Catalysis

J. Am. Chem. Soc., 122, 10521-10532 (2000)

281. M. Takamura, Y. Hamashima, H. Usuda, M. Kanai and M. Shibasaki

A Catalytic Asymmetric Strecker-type Reaction Promoted by Lewis Acid-Lewis Base Bifunctional Catalyst

Chem. Pharm. Bull., 48, 1586-1592 (2000)

282. S. Matsunaga, T. Ohshima and M. Shibasaki

Immobilization of Asymmetric Multifunctional Catalysts on an Insoluble Polymer 
Tetrahedron Lett., 41, 8473-8478 (2000)

283. T. Nemoto, T. Ohshima and M. Shibasaki

Enantioselective Total Syntheses of Novel PKC Activator (+)-Decursin and Its Derivatives Using Catalytic Asymmetric Epoxidation of an Enone

Tetrahedron Lett., 41, 9569-9574 (2000)

284. M. Shibasaki

Synthetic Organic Chemistry in the $21^{\text {st }}$ Century

Chemistry Today, 5, 36-37 (2000)

285. Y. Hamashima, D. Sawada, H. Nogami, M. Kanai and M. Shibasaki

Highly Enantioselective Cyanosilylation of Aldehydes Catalyzed by a Lewis Acid-Lewis Base Bifunctional Catalyst

Tetrahedron, 57, 805-814 (2001)

286. N. Yoshikawa and M. Shibasaki

Direct Catalytic Asymmetric Aldol Reactions Promoted by Novel Heterobimetallic Catalysts Possessing Strong Brønsted Base: A New Strategy for the Development of Lewis Acid-Brønsted Base Bifunctinal Catalysts

Tetrahedron, 57, 2569-2579 (2001)

287. H. Nogami, S. Matsunaga, M. Kanai and M. Shibasaki

Enantioselective Strecker-type Reaction Promoted by Polymer-supported Bifunctional Catalyst

Tetrahedron Lett., 42, 279-283 (2001)

288. Y. Hamashima, M. Kanai and M. Shibasaki

Catalytic Enantioselective Cyanosilylation of Ketones: Improvement of Enantioselectivity and Catalyst Turn-over by Ligand Tuning

Tetrahedron Lett., 42, 691-694 (2001)

289. S. Yamasaki, M. Kanai and M. Shibasaki

Novel Multiaction of Zr Catalyst: One-Pot Synthesis of $\beta$-Cyanohydrins from Olefins

J. Am. Chem. Soc., 123, 1256-1257 (2001)

290. N. Yoshikawa, N. Kumagai, S. Matsunaga, G. Moll, T. Ohshima, T. Suzuki and M. Shibasaki

Direct Catalytic Asymmetric Aldol Reaction: Synthesis of Either syn- or anti- $\alpha, \beta$-Dihydroxy Ketones

J. Am. Chem. Soc., 123, 2466-2467 (2001)

291. T. Nemoto, T. Ohshima, K. Yamaguchi and M. Shibasaki

Catalytic Asymmetric Epoxidation of Enones Using La-BINOL-Triphenylarsine Oxide Complex: Structural Determination of the Asymmetric Catalyst

J. Am. Chem. Soc., 123, 2725-2732 (2001)

292. H. Sasai, T. Arai, S. Watanabe and M. Shibasaki

Novel Heterobimetallic Asymmetric Catalysis Directing toward Enzymatic Function

Catalysis Today, 62, 17-22 (2001)

293. M. Shibasaki and M. Kanai

Multifunctional Asymmetric Catalysis

Chem. Pharm. Bull., 49, 511-524 (2001)

294. N. Kumagai, S. Matsunaga, N. Yoshikawa, T. Ohshima and M. Shibasaki 
Direct Catalytic Enantio- and Diastereoselective Aldol Reaction Using a Zn-Zn-Linked-BINOL Complex: A. Practical Synthesis of syn-1,2-Diols

Org. Lett., 3, 1539-1542 (2001)

295. G. Manickam, H. Nogami, M. Kanai, H. Gröger and M. Shibasaki

anti- and syn-Selective Cyanosilylation Reactions Promoted by a Sugar-Based Bifunctional Catalyst: Stereoselective Syntheses of Essential Building Blocks for HIV Protease Inhibitors and Bestatin

Synlett, 617-620 (2001)

296. K. Yamada, G. Moll, and M. Shibasaki

The First Enantioselective and Diastereoselective Catalytic Nitro-Mannich Reaction: A New Entry to Chiral Vicinal Diamines

Synlett, 980-982 (2001)

297. M. Takamura, K. Funabashi, M. Kanai, and M. Shibasaki

Catalytic Enantioselective Reissert-type Reaction: Development and Application to the Synthesis of a Potent NMDA Receptor Antagonist (-)-L-689,560 Using a Solid-Supported Catalyst J. Am. Chem. Soc., 123, 6801-6808 (2001)

298. T. Suzuki, N. Yamagiwa, Y. Matsuo, S. Sakamoto, K. Yamaguchi, M. Shibasaki and R. Noyori Catalytic Asymmetric Aldol Reaction of Ketones and Aldehydes Using Chiral Calcium Alkoxides Tetrahedron Lett., 42, 4669-4671 (2001)

299. S. Yamasaki, M. Kanai and M. Shibasaki Zirconium Alkoxides in Catalysis Chem. Eur J., 7, 4066-4073 (2001)

300. T. Nemoto, T. Ohshima and M. Shibasaki Catalytic Asymmetric Synthesis of $\alpha, \beta$-Epoxy Esters, Aldehydes, Amides, and $\gamma, \delta$-Epoxy $\beta$-Keto Esters: Unique Reactivity of $\alpha, \beta$-Unsaturated Carboxylic Acid Imidazolides J. Am. Chem. Soc., 123, 9474-9475 (2001)

301. M. Kanai, Y. Hamashima, M. Takamura and M. Shibasaki

Development and Application of Enantioselective Lewis Acid-Lewis Base Bifunctional Catalyst J. Synth. Org. Chem.Jpn., 59, 767-778 (2001)

302. K. Yabu, S. Masumoto, S. Yamasaki, Y. Hamashima, M. Kanai, W. Du, D. P. Curran and M. Shibasaki

Switching Enantiofacial Selectivities Using One Chiral Source: Catalytic Enantioselective Synthesis of the Key Intermediate for (20S)-Camptothecin Family by (S)-Selective Cyanosilylation of Ketones

J. Am. Chem. Soc., 123, 9908-9909 (2001)

303. K. Funabashi, H. Ratni, M. Kanai and M. Shibasaki

Enantioselective Construction of Quaternary Stereocenter through a Reissert-type Reaction Catalyzed by an Electronically Tuned Bifunctional Catalyst: Efficient Synthesis of Various Biologically Significant Compounds

J. Am. Chem. Soc., 123, 10784-10785 (2001)

304. A. Okada, T. Ohshima and M. Shibasaki

Highly Regioselective Synthesis of Cyclic Enol Silyl Ethers Using Ring-Closing Metathesis Tetrahedron Lett., 42, 8023-8027 (2001) 
305. N. Kumagai, S. Matsunaga and M. Shibasaki

Enantioselective 1,4-Addition of Unmodified Ketone Catalyzed by a Bimetallic Zn-Zn-Linked-BINOL Complex

Org. Lett., 3, 4251-4254 (2001)

306. S. Matsunaga, T. Ohshima and M. Shibasaki

Linked-BINOL - an Approach towards Practical Asymmetric Multifunctional Catalysis Adv. Synth. Catal., 1, 3-15 (2002)

307. A. Sekine, T. Ohshima and M. Shibasaki

An Enantioselective Formal Synthesis of 4-Demethoxydaunomycin Using the Catalytic Asymmetric Ring Opening Reaction of meso-Epoxide with $p$-Anisidine

Tetrahedron, 58, 75-82 (2002)

308. N. Tsuritani, K. Yamada, N. Yoshikawa and M. Shibasaki

Catalytic Asymmetric Syntheses of ICI-199441 and CP-99994 Using Nitro-Mannich Reaction Chem. Lett., 3, 276-277 (2002)

309. T. Nemoto, T. Ohshima and M. Shibasaki

Catalytic Asymmtrtic Epoxidation of $\alpha, \beta$-Unsaturated Carbonyl Compounds

J. Synth. Org. Chem. Jpn., 60, 94-105 (2002)

310. H. Usuda, M. Kanai and M. Shibasaki

Studies toward the Total Synthesis of Garsubelin A: A Concise Synthesis of the 18-epi-Tricyclic Core

Org. Lett., 4, 859-862 (2002)

311. Y. Xu, K. Ohori, T. Ohshima and M. Shibasaki

A Practical Large-scale Synthesis of Enantiomerically Pure 3[Bis(methoxycarbonyl)methyl]cyclohexanone via Catalytic Asymmetric Michael Reaction Tetrahedron, 58, 2585-2588 (2002)

312. N. Yoshikawa, T. Suzuki and M. Shibasaki

Diastereo- and Enantioslective Direct Catalytic Aldol Reaction of 2-Hydroxyacetophenones with Aldehydes Promoted by a Heteropolymetallic Complex: Catalytic Asymmetric Synthesis of anti-1,2-Diols

J. Org. Chem., 67, 2556-2565 (2002)

313. S. Masumoto, K. Yabu, M. Kanai and M. Shibasaki

Practical Synthesis of Chiral Ligands for Catalytic Enantioselective Cyanosilylation of Ketones

Tetrahedron Lett., 43, 2919-2922 (2002)

314. K. Yabu, S. Masumoto, M. Kanai, D. P. Curran and M. Shibasaki

Studies toward Practical Synthesis of (20S)-Camptothecin Family through Catalytic Enantioselective Cyanosilylation of Ketones: Improved Catalyst Efficiency by Ligand-tuning

Tetrahedron Lett., 43, 2923-2926 (2002)

315. H. Usuda, M. Kanai and M. Shibasaki

Studies toward the Total Synthesis of Garsubellin A: Synthesis of 8-Deprenyl-Garsubellin A

Tetrahedron Lett., 43, 3621-3624 (2002)

316. S. Yamasaki, K. Fujii, R. Wada, M. Kanai and M. Shibasaki

A General Catalytic Allylation Using Allyltrimethoxysilane

J. Am. Chem. Soc., 124, 6536-6537 (2002) 
317. M. Shibasaki and N. Yoshikawa

Lanthanide Complexes in Multifunctional Asymmetric Catalysis

Chem. Rev., 102, 2187-2209 (2002)

318. M. Takamura, H. Yanagisawa, M. Kanai and M. Shibasaki

Efficient Synthesis of Antihyperglycemic (S)- $\alpha$-Aryloxy- $\beta$-phenylpropionic Acid Using a Bifunctional Asymmetric Catalyst

Chem. Pharm. Bull., 50, 1118-1121 (2002)

319. R. Takita, T. Ohshima and M. Shibasaki

Highly Enantioselective Catalytic Michael Reaction of $\alpha$-Substituted Malonates Using La-linked-BINOL Complex in the Presence of HFIP (1,1,1,3,3,3-hexafluoroisopropanol)

Tetrahedron Lett., 43, 4661-4665 (2002)

320. M. Shibasaki, M. Kanai and K. Funabashi

Recent Progress in Asymmetric Two-Center Catalysis

Chem. Commun., 1989-1999 (2002)

321. R. Wada, Y. Suto, M. Kanai and M. Shibasaki

Dramatic Switching of Protein Kinase C Agonist/Antagonist Activity by Modifying the 12-Ester Side Chain of Phorbol Esters

J. Am. Chem. Soc., 124, 10658-10659 (2002)

322. N. Yoshikawa and M. Shibasaki

Catalytic Asymmetric Synthesis of $\beta$-Hydroxy- $\alpha$-amino Acid Esters by Direct Aldol Reaction of Glycinate Schiff Bases

Tetrahedron, 58, 8289-8298 (2002)

323. J. Tian, N. Yoshikawa, S. Matsunaga and M. Shibasaki

Asymmetric Cyanation Reaction and Sequential Asymmetric Cyanation-Nitroaldol Reaction Using a [YLi ${ }_{3}\{$ (binaphthoxide)\}] Single Catalyst Component: Catalyst Tuning with Achiral Additives

Angew. Chem. Int. Ed., 41, 3636-3638 (2002)

324. M. Shibasaki, M. Kanai, T. Ohshima and T. Nemoto

Development of New Asymmetric Reactions Using Rare Earths Containing Asymmetric Catalysts RARE EARTHS, 41, 37-42 (2002)

325. M. Kanai, A. Kuramochi and M. Shibasaki

Enhancement of Lewis Acidity by Ligand-Defined Metal Geometry: A Catalytic Allylation of Aldehydes with Allyltrimethylsilane

Synthesis, 1956-1958 (2002)

326. S. Masumoto, M. Suzuki, M. Kanai and M. Shibasaki

A Practical Synthesis of $(S)$-Oxybutynin

Tetrahedron Lett., 43, 8647-8651 (2002)

327. T. Nemoto, H. Kakei, V. Gnanadesikan, S. Tosaki, T. Ohshima and M. Shibasaki

Catalytic Asymmetric Epoxidatin of $\alpha, \beta$-Unsaturated Amides: Efficient Synthesis of $\beta$-Aryl $\alpha$-Hydroxy Amides Using a One-Pot Tandem Catalytic Asymmetric Epoxidation-Pd-Catalyzed Epoxide Opening Process

J. Am. Chem. Soc., 124, 14544-14545 (2002)

328. T. Ohshima, Y. Xu, R. Takita, S. Shimizu, D. Zhong and M. Shibasaki 
Enantioselective Total Synthesis of (-)-Strychnine Using the Catalytic Asymmetric Michael Reaction and Tandem Cyclization

J. Am. Chem. Soc., 124, 14546-14547 (2002)

329. T. Mizutani, S. Honzawa, S. Tosaki and M. Shibasaki

Total Synthesis of $( \pm)$-Wortmannin

Angew. Chem. Int. Ed., 41, 4680-4682 (2002)

330. T. Shibuguchi, Y. Fukuta, Y. Akachi, A. Sekine, T. Ohshima and M. Shibasaki

Development of New Asymmetric Two-Center Catalysts in Phase-Transfer Reactions

Tetrahedron Lett., 43, 9539-9543 (2002)

331. K. Yabu, S. Masumoto, M. Kanai, W. Du, D. P. Curran and M. Shibasaki

Camptothecin Intermediates Using Cyanosilylation of Ketones Promoted by D-Glucose-derived Lanthanide Catalyst

Heterocycles, 59, 369-385 (2003)

332. N. Kumagai, S. Matsunaga, T. Kinoshita, S. Harada, S. Okada, S. Sakamoto, K. Yamaguchi and M. Shibasaki

Direct Catalytic Asymmetric Aldol Reaction of Hydroxyketones: Asymmetric Zn Catalysis with a $\mathrm{Et}_{2} \mathrm{Zn} /$ Linked-BINOL Complex

J. Am. Chem. Soc., 125, 2169-2178 (2003)

333. S. Tosaki, T. Nemoto, T. Ohshima and M. Shibasaki

Catalytic Asymmetric Synthesis of Both syn- and anti-3, 5-Dihydroxy Esters: Application to 1,3-Polyol/ $\alpha$-Pyrone Natural Product Synthesis

Org. Lett., 5, 495-498 (2003)

334. S. Harada, N. Kumagai, T. Kinoshita, S. Matsunaga and M. Shibasaki

Direct Catalytic Asymmetric Michael Reaction of Hydroxyketones: Asymmetric Zn Catalysis with a $\mathrm{Et}_{2} \mathrm{Zn} /$ Linked-BINOL Complex

J. Am. Chem. Soc., 125, 2582-2590 (2003)

335. K. Fujii, K. Maki, M. Kanai and M. Shibasaki

Formal Catalytic Asymmetric Total Synthesis of Fostriecin

Org. Lett., 5, 733-736 (2003)

336. M. Takamura, K. Yabu, T. Nishi, H. Yanagisawa, M. Kanai and M. Shibasaki

Efficient Synthesis of a Key Intermediate of Neurokinin Receptor Antagonists Using a Bifunctional Asymmetric Catalyst

Synlett, 353-356 (2003)

337. T. Nemoto, S. Tosaki, T. Ohshima and M. Shibasaki

Unique Reactivity of $\alpha, \beta$-Unsaturated Carboxylic Acid Imidazolides: Catalytic Asymmetric Synthsis of $\alpha, \beta$-Epoxy Esters and $\alpha, \beta$-Epoxy Carboxylic Acid Derivatives

Chirality, 15, 306-311 (2003)

338. S. Matsunaga, N. Kumagai, S. Harada and M. Shibasaki

anti-Selective Direct Catalytic Asymmetric Mannich-type Reaction of Hydroxyketone Providing $\beta$-Amino Alcohols

J. Am. Chem. Soc., 125, 4712-4713 (2003)

339. S. Masumoto, H. Usuda, M. Suzuki, M. Kanai and M. Shibasaki

Catalytic Enantioselective Strecker Reaction of Ketoimines 
J. Am. Chem. Soc., 125, 5634-5635 (2003)

340. K. Oisaki, Y. Suto, M. Kanai and M. Shibasaki

A New Method for the Catalytic Aldol Reaction to Ketones

J. Am. Chem. Soc., 125, 5644-5645 (2003)

341. T. Nemoto, T. Ohshima and M. Shibasaki

Enantioselective Total Syntheses of (+)-Decursin and Related Natural Compounds Using Catalytic Asymmetric Epoxidation of an Enone

Tetrahedron, 59, 6889-6897 (2003)

342. J. Tian, N. Yamagiwa, S. Matsunaga and M. Shibasaki

Efficient Two-Step Conversion of $\alpha, \beta$-Unsaturated Aldehydes to Optically Active $\gamma$-Oxy- $\alpha, \beta$-unsaturated Nitriles and Its Application to the Total Synthesis of (+)-Patulolide C Org. Lett., 5, 3021-3024 (2003)

343. Y. Suto, N. Kumagai, S. Matsunaga, M. Kanai and M. Shibasaki

Direct Catalytic Aldol-Type Reactions Using $\mathrm{RCH}_{2} \mathrm{CN}$

Org. Lett., 5, 3147-3150 (2003)

344. T. Ohshima, V. Gnanadesikan, T. Shibuguchi, Y. Fukuta, T. Nemoto and M. Shibasaki Enantioselective Syntheses of Aeruginosin 298-A and Its Analogues Using a Catalytic Asymmetric Phase-Transfer Reaction and Epoxidation

J. Am. Chem. Soc., 125, 11206-11207 (2003)

345. T. Kinoshita, S. Okada, S. R. Park, S. Matsunaga and M. Shibasaki

Sequential Wittig Olefination-Catalytic Asymmetric Epoxidation with Reuse of Waste $\mathrm{Ph}_{3} \mathrm{P}(\mathrm{O})$ : Application of $\alpha, \beta$-Unsaturated $N$-Acyl Pyrroles as Ester Surrogates

Angew. Chem. Int. Ed., 42, 4680-4684 (2003)

346. K. Funabashi, M. Jachmann, M. Kanai and M. Shibasaki

Multicenter Strategy for the Development of Catalytic Enantioselective Nucleophic Alkylation of Ketones: $\mathrm{Me}_{2} \mathrm{Zn}$ Addition to $\alpha$-Ketoesters

Angew. Chem. Int. Ed., 42, 5489-5492 (2003)

347. K. Majima, R. Takita, A. Okada, T. Ohshima and M. Shibasaki

Catalytic Asymmetric Michael Reaction of $\beta$-Keto Esters: Effects of the Linker Heteroatom in Linked-BINOL

J. Am. Chem. Soc., 125, 15837-15845 (2003)

348. N. Yamagiwa, S. Matsunaga and M. Shibasaki

Heterobimetallic Catalysis in Asymmetric 1,4-Addition of $O$-Alkylhydroxylamine to Enones

J. Am. Chem. Soc., 125, 16178-16179 (2003)

349. T. Ohshima, T. Nemoto, S. Tosaki, H. Kakei, V. Gnanadesikan and M. Shibasaki

Catalytic Asymmetric Epoxidation of $\alpha, \beta$-Unsaturated Carboxylic Acid Imidazolides and Amides by Lanthanide-BINOL Complexes

Tetrahedron, 59, 10485-10497 (2003)

350. H. Kakei, T. Nemoto, T. Ohshima and M. Shibasaki

Efficient Synthesis of Chiral $\alpha$ - and $\beta$-Hydroxy Amides: Application to the Synthesis of $(R)$-Fluoxetine

Angew. Chem. Int. Ed., 43, 317-320 (2004) 
351. N. Kumagai, S. Matsunaga and M. Shibasaki

An Efficient Synthesis of Bicyclic Amidines by Intramolecular Cyclization

Angew. Chem. Int. Ed., 43, 478-482 (2004)

352. N. Kato, M. Suzuki, M. Kanai and M. Shibasaki

General and Practical Catalytic Enantioselective Strecker Reaction of Ketoimines: Significant Improvement through Catalyst Tuning by Protic Additives

Tetrahedron Lett., 45, 3147-3151 (2004)

353. N. Kato, M. Suzuki, M. Kanai and M. Shibasaki

Catalytic Enantioselective Strecker Reaction of Ketoimines Using Catalytic Amount of TMSCN and Stoichiometric Amount of HCN

Tetrahedron Lett., 45, 3153-3155 (2004)

354. S. Tosaki, Y. Horiuchi, T. Nemoto, T. Ohshima and M. Shibasaki

Strategy for Enantio- and Diastereoselective Syntheses of All Possible Stereoisomers of 1,3-Polyol Arrays Based on a Highly Catalyst-Controlled Epoxidation of $\alpha, \beta$-Unsaturated Morpholinyl Amides: Application to Natural Product Synthesis

Chem. Eur. J., 10, 1527-1544 (2004)

355. M. Shibasaki, M. Kanai and T. Ohshima

Catalytic Asymmetric Total Synthesis of (-)-Strychnine and Fostriecin

Strat. Tactics Org. Synth., 4, 347-363 (2004)

356. Y. Fukuta, T. Ohshima, V. Gnanadesikan, T. Shibuguchi, T. Nemoto, T. Kisugi, T. Okino and M. Shibasaki

Enantioselective Syntheses and Biological Studies of Aeruginosin 298-A and Its Analogs: Application of Catalytic Asymmetric Phase-Transfer Reaction

Proc. Natl. Acad. Sci. USA, 101, 5433-5438 (2004)

357. Y. Tamaruya, M. Suzuki, G. Kamura, M. Kanai, K. Hama, K. Shimizu, J. Aoki, H. Arai and M. Shibasaki

Identifying Specific Conformations by Using a Carbohydrate Scaffold: Discovery of Subtype-Selective LPA-Receptor Agonists and an Antagonist

Angew. Chem. Int. Ed., 43, 2834-2837 (2004)

358. S. Matsunaga, T. Kinoshita, S. Okada, S. Harada and M. Shibasaki

Catalytic Asymmetric 1,4-Addition Reactions Using $\alpha, \beta$-Unsaturated $N$-Acylpyrroles as Highly

Reactive Monodentate $\alpha, \beta$-Unsaturated Ester Surrogates

J. Am. Chem. Soc., 126, 7559-7570 (2004)

359. V. Gnanadesikan, Y. Horiuchi, T. Ohshima, and M. Shibasaki

Direct Catalytic Asymmetric Aldol-Tishchenko Reaction

J. Am. Chem. Soc., 126, $7782-7783$ (2004)

360. S. Matsunaga, T. Yoshida, H. Morimoto, N. Kumagai, and M. Shibasaki

Direct Catalytic Asymmetric Mannich-type Reaction of Hydroxyketone Using a $\mathrm{Et}_{2} \mathrm{Zn} /$ Linked-BINOL Complex: Synthesis of Either anti- or syn- $\beta$-Amino Alcohols

J. Am. Chem. Soc., 126, 8777-8785 (2004)

361. R. Wada, K. Oisaki, M. Kanai, and M. Shibasaki

Catalytic Enantioselective Allylboration of Ketones

J. Am. Chem. Soc., 126, 8910-8911 (2004) 
362. T. Ohshima, T. Shibuguchi, Y. Fukuta, and M. Shibasaki

Catalytic Asymmetric Phase-Transfer Reactions Using Tartrate-Derived Asymmetric Two-Center Organocatalysts

Tetrahedron, 60, 7743-7754 (2004)

363. N. Yamagiwa, S. Matsunaga, and M. Shibasaki

Mechanistic Studies of a Reaction Promoted by the [YLi $\mathrm{YL}_{3}\{\operatorname{tris}($ binaphthoxide) $\}]$ Complex: Are Three 1,1'-Bi-2-naphthol Units in a Rare-Earth-Alkali-Metal Heterobimetallic Complex Necessary?

Angew. Chem. Int. Ed., 43, 4493-4497 (2004)

364. N. Kato, D. Tomita, K. Maki, M. Kanai, and M. Shibasaki

Practical Synthesis of Chiral Ligands for Catalytic Enantioselective Cyanosilylation of Ketones and Ketoimines

J. Org. Chem., 69, 6128-6130 (2004)

365. E. Ichikawa, M. Suzuki, K. Yabu, M. Albert, M. Kanai, and M. Shibasaki

New Entries in Lewis Acid-Lewis Base Bifunctional Asymmetric Catalyst: Catalytic Enatioselective Reissert Reaction of Pyridine Derivatives

J. Am. Chem. Soc., 126, 11808-11809 (2004)

366. T. Ohshima, Y. Xu, R. Takita, and M. Shibasaki

Enantioselective Total Synthesis of (-)-Strychnine: Development of a Highly Practical Catalytic Asymmetric Carbon-Carbon Bond Formation and Domino Cyclization

Tetrahedron, 60, 9569-9588 (2004)

367. S. Masumoto, M. Suzuki, M. Kanai, and M. Shibasaki

Catalytic Asymmetric Synthesis of $(S)$-Oxybutynin and a Versatile Intermediate for Antimuscarinic Agents

Tetrahedron, 60, 10497-10504 (2004)

368. M. Shibasaki, E. M. Vogl, and T. Ohshima

Asymmetric Heck Reaction

Adv. Synth. Catal., 346, 1533-552 (2004)

369. N. Kumagai, S. Matsunaga, and M. Shibasaki

Cooperative Catalysis of a Cationic Ruthenium, Amine Base, and Na Salt: Catalytic Activation of Acetonitrile as a Nucleophile

J. Am. Chem. Soc., 126, 13632-13633 (2004)

370. H. Usuda, A. Kuramochi, M. Kanai, and M. Shibasaki

Challenge toward Structural Complexity Using Asymmetric Catalyst: Target-Oriented Development of Catalytic Enantioselective Diels-Alder Reaction

Org. Lett., 6, 4387-4390 (2004)

371. Y. Abiko, N. Yamagiwa, M. Sugita, J. Tian, S. Matsunaga, and M. Shibasaki

Catalytic Asymmetric Cyano-Phosphorylation of Aldehydes Promoted by Heterobimetallic $\mathrm{Yli}_{3}$ tris(binaphthoxide) (YLB) Complex

Synlett, 2434-2436 (2004)

372. T. Mita, K. Sasaki, M. Kanai and M. Shibasaki

Catalytic Enantioselective Conjugate Addition of Cyanide to $\alpha, \beta$-Unsaturated $N$-Acylpyrroles

J. Am. Chem. Soc., 127, 514-515 (2004) 
373. S. Tosaki, R. Tsuji, T. Ohshima, and M. Shibasaki

Dynamic Ligand Exchange of the Lanthanide Complex Leading to Structural and Functional Transformation: One-Pot Sequential Catalytic Asymmetric Epoxidation-Regioselective Epoxide Opening Process

J. Am. Chem. Soc., 127, 2147-2155 (2005)

374. N. Yamagiwa, J. Tian, S. Matsunaga, and M. Shibasaki

Catalytic Asymmetric Cyano-Ethoxycarbonylation Reaction of Aldehydes Using a Yli $_{3}$ Tris(binaphthoxide) (YLB) Complex: Mechanism and Roles of Achiral Additives J. Am. Chem. Soc., 127, 3413-3422 (2005)

375. D. Tomita, R. Wada, M. Kanai, and M. Shibasaki Enantioselective Alkenylation and Phenylation Catalyzed by a Chiral CuF Complex J. Am. Chem. Soc., 127, 4138-4139 (2005)

376. R. Takita, Y. Fukuta, R. Tsuji, T. Ohshima and M. Shibasaki

A New Entry in Catalytic Alkylation of Aldehydes and Ketones: Dual Activation of Soft Nucleophiles and Hard Electrophiles by an Indium(III) Catalyst

Org. Lett., 7, 1363-1366 (2005)

377. H. Shigehisa, T. Mizutani, S. Tosaki, T. Ohshima, and M. Shibasaki

Formal Total Synthesis of (+)-Wortmannin Using Catalytic Asymmetric Intramolecular Aldol Condensation Reaction

Tetrahedron Lett., 61, 5057-5065 (2005)

378. K. Oisaki, D. Zhao, Y. Suto, M. Kanai and M. Shibasaki

New Chiral Bis(diphenylphospholane) Ligands: Design, Synthesis, and Application to Catalytic Enantioselective Aldol Reaction to Ketones

Tetrahedron Lett., 46, 4325-4329 (2005)

379. T. Yoshida, H. Morimoto, N. Kumagai, S. Matsunaga, and M. Shibasaki

Non- $\mathrm{C}_{2}$-Symmetric, Chirally Economical, and Readily Tunable Linked-Binols: Desigh and Application in a Direct Catalytic Asymmetric Mannich-type Reaction Angew. Chem. Int. Ed., 44, 3470-3474 (2005)

380. M. Suzuki, N. Kato, M. Kanai, and M. Shibasaki

Catalytic Enantioselective Synthesis of Key Intermediates for Triazole Antifungal Agents

Org. Lett., 13, 2527-2530 (2005)

381. H. Kakei, R. Tsuji, T. Ohshima, and M. Shibasaki

Catalytic Asymmetric Epoxidation of $\alpha, \beta$-Unsaturated Esters Using an Yttrium-Biphenyldiol Complex

J. Am. Chem. Soc., 127, 8962-8963 (2005)

382. S. Harada, S. Handa, S. Matsunaga, and M. Shibasaki

Direct Catalytic Asymmetric Mannich-type Reactions of $N$-(2-Hydroxyacetyl)-pyrroles as an Ester-Equivalent Donor

Angew. Chem. Int. Ed., 44, 4365-4368 (2005)

383. N. Kumagai, S. Matsunaga, and M. Shibasaki

Catalytic Chemoselective Addition of Acetonitrile to Enolizable Aldehydes with Cationic Ru Complex/DBU Combination

Chem. Commun., 3600-3602 (2005) 
384. K. Majima, S. Tosaki, T. Ohshima, and M. Shibasaki

Enantio- and Diastereoselective Construction of Vicinal Quaternary and Tertiary Carbon Centers by Catalytic Michael Reaction of $\alpha$-Substituted $\beta$-Keto Esters to Cyclic Enones

Tetrahedron Lett., 46, 5377-5381 (2005)

385. M. Kanai, N. Kato, E. Ichikawa, and M. Shibasaki

Power of Cooperativity: Lewis Acid-Lewis Base Bifunctional Asymmetric Catalysis Synlett, 1491-1508 (2005)

386. A. Okada, T. Shibuguchi, T. Ohshima, H. Masu, K. Yamaguchi, and M. Shibasaki

Enantio- and Diastereoselective Catalytic Mannich-type Reaction of a Glycine Schiff Base Using a Chiral Two-Center Phase-Transfer Catalyst

Angew. Chem. Int. Ed., 44, 4564-4567 (2005)

387. T. Mita, I. Fujimori, R. Wada, J. Wen, M. Kanai, and M. Shibasaki

Catalytic Enantioselective Desymmetrization of meso- $N$-Acylaziridines with TMSCN

J. Am. Chem. Soc., 127, 11252-11253 (2005)

388. Y. Suto, R. Tsuji, M. Kanai and M. Shibasaki

$\mathrm{Cu}(\mathrm{I})$-Catalyzed Direct Enantioselective Cross Aldol-type Reaction of Acetonitrile

Org. Lett., 7, 3757-3760 (2005)

389. Y. Horiuchi, V. Gnanadesikan, T. Ohshima, H. Masu, K. Katagiri, Y. Sei, K. Yamaguchi, and M. Shibasaki

"Dynamic Structural Change of the Self-Assembled Lanthanum Complex Induced by Lithium Triflate for Direct Catalytic Asymmetric Aldol-Tishchenko Reaction"

Chem. Eur. J., 11, 5195-5204 (2005)

390. N. Yamagiwa, H. Qin, S. Matsunaga, and M. Shibasaki

Lewis Acid-Lewis Acid Heterobimetallic Cooperative Catalysis: Mechanistic Studies and Application in Enantioselective Aza-Michael Reaction

J. Am. Chem. Soc., 127, 13419-13427 (2005)

391. R. Takita, K. Yakura, T. Ohshima, and M. Shibasaki

Asymmetric Alkynylation of Aldehydes Catalyzed by an In(III)/BINOL Complex

J. Am. Chem. Soc., 127, 13760-13761 (2005)

392. A. Kuramochi, H. Usuda, K. Yamatsugu, M. Kanai, and M. Shibasaki

Total Synthesis of $( \pm)$-Garsubellin A

J. Am. Chem. Soc., 127, 14200-14201 (2005)

393. M. Sugita, A. Yamaguchi, N. Yamagiwa, S. Handa, S. Matsunaga, and M. Shibasaki syn-Selective Direct Catalytic Asymmetric Mannich-type Reactions of Hydroxyketones Using $\mathrm{Y}\left\{\mathrm{N}\left(\mathrm{SiMe}_{3}\right)_{2}\right\}_{3} /$ Linked-BINOL Complexes

Org. Lett., 23, 5339-5342 (2005)

394. K. Maki, R. Motoki, K. Fujii, M. Kanai, T. Kobayashi, S. Tamura, and M. Shibasaki Catalyst-Controlled Asymmetric Synthesis of Fostriecin and 8-epi-Fostriecin

J. Am. Chem. Soc., 127, 17111-17117 (2005)

395. M. Shibasaki and M. Kanai

Synthetic Strategies of Fostriecin

Heterocycles, 66, 727-741 (2005) 
396. M. Kanai, N. Kato, E. Ichikawa, and M. Shibasaki

Recent Progress in Lewis Acid-Lewis Base Bifunctional Asymmetric Catalysis

Pure Appl.Chem., 77, 2047-2052 (2005)

397. N. Fukuda, K. Sasaki, T. V. R. S. Sastry, M. Kanai, and M. Shibasaki

Catalytic Asymmetric Total Synthesis of (+)-Lactacystin

J. Org. Chem., 71, 1220-1225 (2006)

398. H. Qin, N. Yamagiwa, S. Matsunaga, and M. Shibasaki

Bismuth-Catalyzed Intermolecular Hydroamination of 1,3-Dienes with Carbamates, Sulfonamides, and Carboxamides

J. Am. Chem. Soc., 128, 1611-1614 (2006)

399. D. Zhao, K. Oisaki, M. Kanai, and M. Shibasaki

Catalytic Enantioselective Intermolecular Reductive Aldol Reaction to Ketones

Tetrahedron Lett., 47, 1403-1407 (2006)

400. M. Shibasaki

Chiral Poly-Rare Earth Metal Complexes in Asymmetric Catalysis

Proc. Jpn. Acad. Ser. B, 82, 72-85 (2006)

401. M. Shibasaki and S. Matsunaga

Design and Application of Linked-BINOL Chiral Ligands in Bifunctional Asymmetric Catalysis

Chem. Soc. Rev., 35, 269-279 (2006)

402. M. Shibasaki, M. Kanai, and S. Matsunaga

Chiral, Poly(Rare-Earth Metal) Complexes in Asymmetric Catalysis

Aldrichimica Acta, 39, 31-39 (2006)

403. Y. Fukuta, T. Mita, N. Fukuda, M. Kanai and M. Shibasaki

De Novo Synthesis of Tamiflu via a Catalytic Asymmetric Ring-Opening of meso-Aziridines with $\mathrm{TMSN}_{3}$

J. Am. Chem. Soc., 128, 6312-6313 (2006)

404. N. Yamagiwa, Y. Abiko, M. Sugita, J. Tian, S. Matsunaga, and M. Shibasaki

Catalytic Asymmetric Cyano-phosphorylation of Aldehydes Using a $\mathrm{YLi}_{3}$ tris(binaphthoxide) Complex (YLB)

Tetrahedron: Asymmetry, 17, 566-573 (2006)

405. M. Shibasaki and S. Matsunaga

Metal/linked-BINOL Complexes: Applications in Direct Catalytic Asymmetric Mannich-type Reactions

J. Organomet. Chem., 691, 2089-2100 (2006)

406. H. Morimoto, S. H. Wiedemann, A. Yamaguchi, S. Harada, Z. Chen, S. Matsunaga, and M. Shibasaki

Trichloromethyl Ketones as Synthetically Versatile Donors: Application in Direct Catalytic Mannich-type Reactions and the Stereoselective Synthesis of Azetidines

Angew. Chem. Int. Ed., 45, 3146-3150 (2006)

407. A. Yamaguchi, S. Matsunaga, and M. Shibasaki

Direct Catalytic Asymmetric Mannich-type Reactions of Isomerizable Aliphatic Imines: Chemoselective Enolate Formation from a Hydroxyketone by a Zn-catalyst

Tetrahedron Lett., 47, 3985-3989 (2006) 
408. N. Kato, T. Mita, M. Kanai, B. Therrien, M. Kawano, K. Yamaguchi, H. Danjo, Y. Sei, A. Sato, S. Furusho, and M. Shibasaki

Assembly State of Catalytic Modules as Chiral Switches in Asymmetric Strecker Amino Acid Synthesis

J. Am. Chem. Soc., 128, 6768-6769 (2006)

409. K. Oisaki, D. Zhao, M. Kanai, and M. Shibasaki

Catalytic Enantioselective Aldol Reaction to Ketones

J. Am. Chem. Soc., 128, 7164-7165 (2006)

410. S. Matsunaga, H. Qin, M. Sugita, S. Okada, T. Kinoshita, N. Yamagiwa, and M. Shibasaki

Catalytic Asymmetric Epoxidation of $\alpha, \beta$-Unsaturated $N$-Acylpyrroles as Monodentate and Activated Ester Equivalent Acceptors

Tetrahedron, 62, 6630-6639 (2006)

411. R. Wada, T. Shibuguchi, S. Makino, K. Oisaki, M. Kanai, and M. Shibasaki

Catalytic Enantioselective Allylation of Ketoimines

J. Am. Chem. Soc., 128, 7687-7691 (2006)

412. T. Shibuguchi, H. Mihara, A. Kuramochi, S. Sakuraba, T. Ohshima, and M. Shibasaki

Short Synthesis of (+)-Cylindricine C by Using a Catalytic Asymmetric Michael Reaction with a Two-Center Organocatalyst

Angew. Chem. Int. Ed., 45, 4635-4637 (2006)

413. D. Tomita, M. Kanai, and M. Shibasaki

Nucleophilic Activation of Alkenyl and Aryl Boronates by a Chiral CuF Complex: Catalytic Enantioselective Alkenylation and Arylation of Aldehydes

Chem. Asian J., 1, 161-166 (2006)

414. M. Shibasaki, M. Kanai, and S. Matsunaga

Development of Catalytic Asymmetric Reactions Using Chiral Multifunctional Rare-Earth Metal Catalysts

TCI Mail, 131, 2-13 (2006)

415. S. Tosaki, K. Hara, V. Gnanadesikan, H. Morimoto, S. Harada, M. Sugita, N. Yamagiwa, S. Matsunaga, and M. Shibasaki

Mixed La-Li Heterobimetallic Complexes for Tertiary Nitroaldol Resolution

J. Am. Chem. Soc., 128, 11776-11777 (2006)

416. K. Yamatsugu, R. Motoki, M. Kanai, and M. Shibasaki

Identification of Potent, Selective Protein Kinase C Inhibitors Based on a Phorbol Skeleton

Chem. Asian J., 1, 314-321 (2006)

417. R. Motoki, D. Tomita, M. Kanai, and M. Shibasaki

Catalytic Enantioselective Alkenylation and Phenylation of Trifluoromethyl Ketones

Tetrahedron Lett., 47, 8083-8086 (2006)

418. D. Zhao, K. Oisaki, M. Kanai, and M. Shibasaki

Dramatic Ligand Effect in Catalytic Asymmetric Reductive Aldol Reaction of Allenic Esters to Ketones

J. Am. Chem. Soc., 128, 14440-14441 (2006)

419. W. Itano, T. Ohshima and M. Shibasaki

Synthesis of the Tricyclic Core of 5 $\alpha$-Capnellenols Using Asymmetric Heck Reaction-Carbanion 
Capture Process

Synlett, 3053-3056 (2006)

420. S. Matsunaga, M. Sugita, N. Yamagiwa, S. Handa, A. Yamaguchi, and M. Shibasaki

syn-Selective Direct Catalytic Asymmetric Mannich-type Reactions of Aromatic and Heteroaromatic Hydroxy Ketones Promoted by $\mathrm{Y}\left[\mathrm{N}\left(\mathrm{SiMe}_{3}\right)_{2}\right]_{3} /$ Linked-BINOL Complexes

Bull. Chem. Soc. Jpn., 79, 1906-1912 (2006)

421. I. Fujimori, T. Mita, K. Maki, M. Shiro, A. Sato, S. Furusho, M. Kanai and M. Shibasaki

Key Role of the Lewis Base Position in Asymmetric Bifunctional Catalysis: Design and Evaluation of a New Ligand for Chiral Polymetallic Catalysts

J. Am. Chem. Soc., 128, 16438-16439 (2006)

422. Z. Chen, H. Morimoto, S. Matsunaga, and M. Shibasaki

Catalytic Asymmetric Epoxidation of $\alpha$-Methyl $\alpha, \beta$-Unsaturated Anilides as Ester Surrogates Synlett, 3529-3532 (2006)

423. H. Qin, N. Yamagiwa, S. Matsunaga, and M. Shibasaki

Bismuth-Catalyzed Direct Substitution of the Hydroxy Group in Alcohols with Sulfonamides, Carbamates, and Carboxamides

Angew. Chem. Int. Ed., 46, 409-413 (2007)

424. M. Shibasaki, M. Kanai, and N. Fukuda

Total Synthesis of Lactacystin and Salinosporamide A

Chem. Asian J., 2, 20-38 (2007)

425. T. Mita, N. Fukuda, F. X. Roca, M. Kanai, and M. Shibasaki

Second Generation Catalytic Asymmetric Synthesis of Tamiflu: Allylic Substitution Route

Org. Lett., 9, 259-262 (2007)

426. Y. Suto, M. Kanai, and M. Shibasaki

Catalytic Enantioselective Mannich-type Reactions of Ketoimines

J. Am. Chem. Soc., 129, 500-501 (2007)

427. K. Yamatsugu, S. Kamijo, Y. Suto, M. Kanai, and M. Shibasaki

A Concise Synthesis of Tamiflu: Third Generation Route via the Diels-Alder Reaction and the Curtius Rearrangement

Tetrahedron Lett., 48, 1403-1406 (2007)

428. H. Kakei, R. Tsuji, T. Ohshima, H. Morimoto, S. Matsunaga, and M. Shibasaki

Catalytic Asymmetric Epoxidation of $\alpha, \beta$-Unsaturated Esters with Chiral Yttrium-Biaryldiol Complexes

Chem. Asian J., 2, 257-264 (2007)

429. M. Shibasaki and M. Kanai

Asymmetric Synthesis of Anti-Influenza Drug, Tamiflu

Farumashia, 43, 201-206 (2007)

430. S. Harada, R. Takita, T. Ohshima, S. Matsunaga, and M. Shibasaki

Ligand Accelerated Indium(III)-Catalyzed Asymmetric Alkynylation of Aldehydes with 2-Mmethyl-3-butyn-2-ol as an Ethyne Equivalent Donor

Chem. Commun., 948-950 (2007)

431. S.-Y. Park, H. Morimoto, S. Matsunaga and M. Shibasaki 
Catalytic Asymmetric Michael Reactions of Dibenzyl Malonate to $\alpha, \beta$-Unsaturated $\mathrm{N}$-Acylpyrroles Using a $\mathrm{La}(\mathrm{O}-\mathrm{i} \mathrm{Pr})_{3} / P h$-linked-BINOL Complex

Tetrahedron Lett., 48, 2815-2818 (2007)

432. S. Handa, V. Gnanadesikan, S. Matsunaga, and M. Shibasaki

Syn-Selective Catalytic Asymmetric Nitro-Mannich Reactions Using a Heterobimetallic $\mathrm{Cu}-\mathrm{Sm}-\mathrm{Schiff}$ Base Complex

J. Am. Chem. Soc., 129, 4900-4901 (2007)

433. K. Maki, M. Kanai, and M. Shibasaki

Pd-Catalyzed Allylic Alkylation of Secondary Nitroalkanes

Tetrahedron, 63, 4250-4257 (2007)

434. H. Mihara, T. Shibuguchi, A. Kuramochi, T. Ohshima, and M. Shibasaki

Short Synthesis of (+)-Cylindricine C and Formal Total Synthesis of (-)-Lepadiformine

Heterocyceles, 72, 421-438 (2007)

435. M. Kanai and M. Shibasaki

Catalytic Asymmetric Synthesis of Biologically Active Molecules

J. Synth. Org. Chem. Jpn., 65, 439-449 (2007)

436. Y. Shimizu, A. Kuramochi, H. Usuda, M. Kanai, and M. Shibasaki

A New Approach for the Construction of a Highly Congested Bicyclic System in Polycyclic Polyprenylated Acylphloroglucinols (PPAPs)

Tetrahedron Lett., 48, 4173-4177 (2007)

437. I. Fujimori, T. Mita, K. Maki, M. Shiro, A. Sato, S. Furusho, M. Kanai and M. Shibasaki

Toward a Rational Design of the Assembly Structure of Polymetallic Asymmetric Catalysts: Design, Synthesis, and Evaluation of New Chiral Ligands for Catalytic Asymmetric Cyanation Reactions

Tetrahedron, 63, 5820-5831 (2007)

438. K. Oisaki, D. Zhao, M. Kanai, and M. Shibasaki

Catalytic Enantioselective Alkylative Aldol Reaction: Efficient Multicomponent Assembly of Dialkylzincs, Allenic Esters, and Ketones toward Highly Functionalized $\delta$-Lactones with Tetrasubstituted Chiral Centers

J. Am. Chem. Soc., 129, 7439-7443 (2007)

439. N. Kumagai, S. Matsunaga, and M. Shibasaki

Catalytic Nucleophilic Activation of Acetonitrile via Cooperative Catalysis of Cationic Ru Complex, DBU, and $\mathrm{NaPF}_{6}$

Tetrahedron, 63, 8598-8608 (2007)

440. R. Motoki, M. Kanai, and M. Shibasaki

Copper(I) Alkoxide-Catalyzed Alkynylation of Trifluoromethyl Ketones

Org. Lett., 9, 2997-3000 (2007)

441. H. Morimoto, G. Lu, N. Aoyama, S. Matsunaga, and M. Shibasaki

Lanthanum Aryloxide/Pybox-Catalyzed Direct Asymmetric Mannich-type Reactions Using a Trichloromethyl Ketone as a Propionate Equivalent Donor

J. Am. Chem. Soc., 129, 9588-9589 (2007)

442. M. Shibasaki and M. Kanai

Catalytic Enantioselective Construction of Tetrasubstituted Carbons by Self-Assembled Poly Rare 
Earth Metal Complexes

Org. Biomol. Chem., 5, 2027-2039 (2007)

443. H. Qin, N. Yamagiwa, S. Matsunaga, and M. Shibasaki

Bismuth- and Hafnium-Catalyzed Hydroamination of Vinyl Arenes with Sulfonamides, Carbamates, and Carboxamides

Chem. Asian J., 2, 150-154 (2007)

444. T. Shibuguchi, H. Mihara, A. Kuramochi, T. Ohshima, and M. Shibasaki

Catalytic Asymmetric Phase-Transfer Michael Reaction and Mannich-type Reaction of Glycine Schiff Bases with Tartrate-Derived Diammonium Salts

Chem. Asian J., 2, 794-808 (2007)

445. A. Yamaguchi, N. Aoyama, S. Matsunaga, and M. Shibasaki

Ba-catalyzed Direct Mannich-type Reactions of a $\beta, \gamma$-Unsaturated Ester Providing $\beta$-Methyl aza-Morita-Baylis-Hillman-type Products

Org. Lett., 9, 3387-3390 (2007)

446. T. Mashiko, K. Hara, D. Tanaka, Y. Fujiwara, N. Kumagai and M. Shibasaki

En Route to an Efficient Catalytic Asymmetric Synthesis of AS-3201

J. Am. Chem. Soc., 129, 11342-11343 (2007)

447. H. Kakei, T. Sone, Y. Sohtome, S. Matsunaga and M. Shibasaki

Catalytic Asymmetric Cyclopropanation of Enones With Dimethyloxosulfonium Methylide Promoted by a $\mathrm{La}_{-} \mathrm{Li}_{3}$-(Biphenyldiolate $)_{3}+\mathrm{NaI}$ Complex

J. Am. Chem. Soc., 129, 13410-13411 (2007)

448. M. Shibasaki and T. Ohshima

Recent Studies on the Synthesis of Strychnine

The Alkaloids, 64, 103-138 (2007)

449. R. Takita, S. Harada, T. Ohshima, S. Matsunaga, and M. Shibasaki

Catalytic Enantioselective Addition of Terminal Alkynes to Aldehydes: Preparation of $(S)-(-)-1,3-D i p h e n y l-2-p r o p y n-1-o l$ and $(S)-(-)-4-M e t h y l-1-p h e n y l-2-p e n t y n-1,4-d i o l$

Org. Synth., 85, 118-130 (2008)

450. S. Matsunaga and M. Shibasaki

Multimetallic Bifunctional Asymmetric Catalysis Based on Proximity Effect Control

Bull. Chem. Soc. Jpn., 81, 60-75 (2008)

451. M. Morita, T. Sone, K. Yamatsugu, Y. Sohtome, S. Matsunaga, M. Kanai, Y. Watanabe, and M. Shibasaki

A Method for the Synthesis of an Oseltamivir PET Tracer

Bioorg. Med. Chem. Lett., 18, 600-602 (2008)

452. H. Mihara, Y. Sohtome, S, Matsunaga, and M. Shibasaki

Chiral-Catalyst-Base Convergent Synthesis of HIV Protease Inhibitor GRL-06579A

Chem. Asian J., 3, 359-366 (2008)

453. T. Nitabaru, N. Kumagai, and M. Shibasaki

A Catalytic Asymmetric anti-Selective Nitroaldol Reaction with a Neodymium-Sodium Heterobimetallic Complex

Tetrahedron Lett., 49, 272-276 (2008) 
454. Z. Chen, H. Morimoto, S. Matsunaga, and M. Shibasaki

A Bench-Stable Homodinuclear $\mathrm{Ni}_{2}$-Schiff Base Complex for Catalytic Asymmetric Synthesis of $\alpha$-Tetrasubstituted anti- $\alpha, \beta$-Diamino Acid Surrogates

J. Am. Chem. Soc., 130, 2170-2171 (2008)

455. M. Shibasaki and M. Kanai

Synthetic Strategies for Oseltamivir Phosphate

Eur.J.Org. Chem., 1839-1850 (2008)

456. S. H. Wiedemann, H. Noda, S. Harada, S. Matsungaga, and M. Shibasaki

$\mathrm{Sc}^{3+}$-Catalyzed Aldol-type Additions of $N$-Benzoylcyclopropanecarboxamides via Iodide-Mediated Ring-Opening: Stereoselective Synthesis of $\gamma$-Lactams

Org. Lett., 10, 1661-1664 (2008)

457. S. Handa, K. Nagawa, Y. Sohtome, S. Matsunaga, and M. Shibasaki

A Heterobimetallic Pd/Schiff Base Complex for anti-Selective Catalytic Asymmetric Nitroaldol Reactions and Applications to Short Syntheses of $\beta$-Adrenoceptor Agonists

Angew. Chem. Int. Ed., 47, 3230-3233 (2008)

458. A. Usami, T. Sasaki, N. Satoh, T. Akiba, S. Yokoshima, T. Fukuyama, K. Yamatsugu, M. Kanai, M. Shibasaki, and N. Matsuki

Oseltamivir Enhances Hippocampal Network Synchronization

J. Pharmacol. Sci., 106, 659-662 (2008)

459. A. Ose, H. Kusuhara, K. Yamatsugu, M. Kanai, M. Shibasaki, T. Fujita, A. Yamamoto, and Y. Sugiyama

P-Glycopotein Restricts the Penetration of Oseltamivir across the Blood-Brain Barrier

Drug Metab. Dispos., 36, 427-434 (2008)

460. A. Nojiri, N. Kumagai, and M. Shibasaki

Asymmetric Catalysis via Dynamic Substrate/Ligand/Rare Earth Metal Conglomerate

J. Am. Chem. Soc., 130, 5630-5631 (2008)

461. Y. Tanaka, M. Kanai and M. Shibasaki

A Catalytic Enantioselective Conjugate Addition of Cyanide to Enones

J. Am. Chem. Soc., 130, 2170-2171 (2008)

462. A. Yamaguchi, S. Matsunaga and M. Shibasaki

Direct Catalytic Asymmetric Mannich-type Reactions of $\gamma$-Butenolides: Effectiveness of Brønsted Acid in Chiral Metal Catalysis

Org. Lett., 10, 2319-2322 (2008)

463. Y. Sohtome, Y. Kato, S. Handa, N. Aoyama, K. Nagawa, S. Matsunaga and M. Shibasaki

Stereodivergent Catalytic Doubly Diastereoselective Nitroaldol Reactions Using Heterobimetallic Complexes

Org. Lett., 10, 2231-2234 (2008)

464. T. Mashiko, N. Kumagai and M. Shibasaki

An Improved Lanthanum Catalyst System for Asymmetric Amination: Toward a Practical Asymmetric Synthesis of AS-3201 (Ranirestat)

Org. Lett., 10, 2725-2728 (2008)

465. T. Sone, A. Yamaguchi, S. Matsunaga and M. Shibasaki

Catalytic Asymmetric Synthesis of 2,2-Disubstituted Terminal Epoxides via 
Dimethyloxosulfonium Methylide Addition to Ketones

J. Am. Chem. Soc., 130, 10078-10079 (2008)

466. Z. Chen, K. Yakura, S. Matsunaga and M. Shibasaki

Direct Catalytic Asymmetric Mannich-type Reaction of $\beta$-Keto Phosphonate Using a Dinuclear $\mathrm{Ni}_{2}$-Schiff Base Complex

Org. Lett., 10, 3239-3242 (2008)

467. M. Shibasaki, S. Matsunaga and N. Kumagai

Strategies for Constructing Diverse Chiral Environments in Multimetallic Bifunctional Asymmetric Catalysis

Synlett, 11, 1583-1602 (2008)

468. G. Lu, H. Morimoto, S. Matsunaga and M. Shibasaki

Chiral $\gamma$-Amino Amide Synthesis by Heterobimetallic Lanthanum/Lithium/Pybox-Catalyzed Direct Asymmetric Mannich-type Reactions of $\alpha$-Keto Anilides

Angew. Chem. Int. Ed., 47, 6847-6850 (2008)

469. M. Shibasaki and M. Kanai

Asymmetric Synthesis of Tertiary Alcohols and $\alpha$-Tertiary Amines via Cu-Catalyzed C-C Bond Formation to Ketones and Ketimines

Chem. Rev., 108, 2853-2873 (2008)

470. K. Hara, S.-Y. Park, N. Yamagiwa, S. Matsunaga and M. Shibasaki

Catalytic Asymmetric Epoxidation of $\alpha, \beta$-Unsaturated Phosphane Oxides with a $\mathrm{Y}(\mathrm{O}-\mathrm{i} \mathrm{Pr})_{3} /$ Biphenyldiol Complex

Chem. Asian J., 3, 1500-1504 (2008)

471. Y. Tanaka, M. Kanai and M. Shibasaki

Catalytic Conjugate Addition of Cyanide to Enones: Cooperative Catalysis of $\mathrm{Ni}(0)$ and $\mathrm{Gd}(\mathrm{OTf})_{3}$ Synlett, 2295-2298 (2008)

472. H. Noda, S. H. Widemann, S. Matsunaga and M. Shibasaki

A DyI ${ }_{3}$-catalyzed Mannich-type Reactions of 1-Methylcyclopropanecarboxylate-type Donors for the Stereoselective Synthesis of Pyrrolidines with Quarternary Stereocenters

Chem. Lett., 37, 1180-1181 (2008)

473. R. Yazaki, T. Nitabaru, N. Kumagai and M. Shibasaki

Direct Catalytic Asymmetric Addition of Allylic Cyanides to Ketoimines

J. Am. Chem. Soc., 130, 14477-14479 (2008)

474. H. Morimoto, T. Yoshino, T. Yukawa, G. Lu, S. Matsunaga and M. Shibasaki

Lewis Base Assisted Brønsted Base Catalysis: Bidentate Phosphine Oxides as Activators and Modulators of Brønsted Basic Lanthanum-Aryloxides

Angew. Chem. Int. Ed., 47, 9125-9129 (2008)

475. I. Chen, K. Oisaki, M. Kanai and M. Shibasaki

$\mathrm{Cu}(\mathrm{I})$-Catalyzed Hetero-Diesls-Alder Reaction between Danishefsky-type Siloxy Dienes and Ketones

Org. Lett., 10, 5151-5154 (2008)

476. Y. Du, L.-W. Xu, Y. Shimizu, K. Oisaki, M. Kanai and M. Shibasaki Asymmetric Reductive Mannich Reaction to Ketimines Catalyzed by a $\mathrm{Cu}(\mathrm{I}) \mathrm{Complex}$ J. Am. Chem. Soc., 130, 16146-16147 (2008) 
477. K. Yamatsugu, L. Yin, S. Kamijo, Y. Kimura, M. Kanai and M. Shibasaki

A Synthesis of Tamiflu Based on a Barium-Catalyzed Asymmetric Diels-Alder-type Reaction Angew. Chem. Int. Ed., 48, 1070-1076 (2009)

478. T. Sone, G. Lu, S. Matsunaga and M. Shibasaki

Catalytic Asymmetric Synthesis of 2,2-Disubstituted Oxetanes from Ketones via One-pot Sequential Addition of Sulfur Ylide

Angew. Chem. Int. Ed., 48, 1677-1680 (2009)

479. Z. Chen, M. Furutachi, Y. Kato, S. Matsunaga and M. Shibasaki

A Stable Homodinuclear Biscobalt(III)-Schiff Base Complex for Catalytic Asymmetric 1,4-Additions of $\beta$-Keto Esters to Alkynones

Angew. Chem. Int. Ed., 48, 2218-2220 (2009)

480. R. Yazaki, N. Kumagai and M. Shibasaki

Direct Catalytic Asymmetric Addition of Allyl Cyanide to Ketones

J. Am. Chem. Soc., 131, 3195-3197 (2009)

481. A. Nojiri, N. Kumagai and M. Shibasaki

Linking Structural Dynamics and Functional Diversity in Asymmetric Catalysis

J. Am. Chem. Soc., 131, 3779-3784 (2009)

482. M. Morita, L. Drouin, R. Motoki, Y. Kimura, I. Fujimori, M. Kanai and M. Shibasaki

Two Methods for Catalytic Generation of Reactive Enolates Promoted by a Chiral Poly Gd Complex: Application to Catalytic Enantioselective Protonation Reactions

J. Am. Chem. Soc., 131, 3858-3859 (2009)

483. K. Hara, S. Tosaki, V. Gnanadesikan, H. Morimoto, S. Harada, M. Sugita, N. Yamagiwa, S. Matsunaga and M. Shibasaki

Mixed La-Li Heterobimetallic Complexes for Tertiary Nitroaldol Resolution

Tetrahedron, 65, 5030-5036 (2009)

484. Y. Xu, G. Lu, S. Matsunaga and M. Shibasaki

Direct anti-Selective Catalytic Asymmetric Mannich-type Reactions of $\alpha$-Keto Anilides for $\gamma$-Amino Amides and Azetidine-2-amides Synthesis

Angew. Chem. Int. Ed., 48, 3353-3356 (2009)

485. Y. Kimura, K. Yamatsugu, M. Kanai and M. Shibasaki

Design and Synthesis of Immobilized Tamiflu Analog on Resin for Affinity Chromatography

Tetrahedron Lett., 50, 3205-3208 (2009)

486. A. Nishikimi, H. Fukuhara, W. Su, T. Hongu, S. Takasuga, H. Mihara, Q. Cao, F. Sanematsu, M. Kanai, H. Hasegawa, Y. Tanaka, M. Shibasaki, Y. Kanaho, T. Sasaki, M. A. Frohman, and Y. Fukui

Sequential Regulation of DOCK2 Dynamics by Two Phospholipids During Neutrophil Chemotaxis

Science, 324, 384-387 (2009)

487. D. Tomita, K. Yamatsugu, M. Kanai, and M. Shibasaki

Enantioselective Synthesis of SM-130686 Based on the Development of Asymmetric $\mathrm{Cu}(\mathrm{I}) \mathrm{F}$ Catalysis to Access 2-Oxindoles Containing a Tetrasubstituted Carbon

J. Am. Chem. Soc., 131, 6946-6948 (2009)

488. Y. Suzuki, R. Yazaki, N. Kumagai and M. Shibasaki 
Direct Catalytic Asymmetric Mannich-type Reaction of Thioamides Angew. Chem. Int. Ed., 48, 5026-5029 (2009)

489. K. Yamatsugu, M. Kanai and M. Shibasaki

An Alternative Synthesis of Tamiflu ${ }^{\circledR}$ : a Synthetic Challenge and the Identification of a Ruthenium-Catalyzed Dihydroxylation Route

Tetrahedron, 65, 6017-6024 (2009)

490. H. Mihara, Y. Xu, N. E. Shepherd, S. Matsunaga and M. Shibasaki

A Heterobimetallic $\mathrm{Ga} / \mathrm{Yb}$-Schiff Base Complex for Catalytic Asymmetric $\alpha$-Addition of Isocyanides to Aldehydes

J. Am. Chem. Soc., 131, 8384-8385 (2009)

491. Y. Kato, M. Furutachi, Z. Chen, H. Mitsunuma, S. Matsunaga and M. Shibasaki

A Homodinuclear $\mathrm{Mn}(\mathrm{III})_{2}$-Schiff Base Complex for Catalytic Asymmetric 1,4-Additions of Oxindoles to Nitroalkenes

J. Am. Chem. Soc., 131, 9168-9169 (2009)

492. L. Yin, M. Kanai and M. Shibasaki

Nucleophile Generation via Decarboxylation: Asymmetric Construction of Contiguous Trisubstituted and Quaternary Stereocenters Through a $\mathrm{Cu}(\mathrm{I})$-Catalyzed Decarboxylative Mannich-type Reaction

J. Am. Chem. Soc., 131, 9610-9611 (2009)

493. A. Yamaguchi, S. Matsunaga and M. Shibasaki

Catalytic Asymmetric Synthesis of $\alpha$-Alkylidene- $\beta$-hydroxy Esters via Dynamic Kinetic Asymmetric Transformation Involving Ba-Catalyzed Direct Aldol Reaction

J. Am. Chem. Soc., 131, 10842-10843 (2009)

494. I. Chen, L. Yin, W. Itano, M. Kanai and M. Shibasaki

Catalytic Asymmetric Synthesis of Chiral Tertiary Organoboronic Esters through Conjugate Boration of $\beta$-Substituted Cyclic Enones

J. Am. Chem. Soc., 131, 11664-11665 (2009)

495. M. Shibasaki, M. Kanai, S. Matsunaga and N. Kumagai

Recent Progress in Asymmetric Bifunctional Catalysis Using Multimetallic Systems

Acc. Chem. Res., 42, 1117-1127 (2009)

496. Y. Kato, Z. Chen, S. Matsunaga and M. Shibasaki

Catalytic Asymmetric Synthesis of Nitrogen-Containing gem-Bisphosphonates Using a Dinuclear $\mathrm{Ni}_{2}$-Schiff Base Complex

Synlett, 1635-1638 (2009)

497. S. Mouri, Z. Chen, S. Matsunaga and M. Shibasaki

Direct Catalytic Asymmetric Aldol Reaction of $\beta$-Keto Esters with Formaldehyde Promoted by a Dinuclear $\mathrm{Ni}_{2}$-Schiff Base Complex

Chem. Commun., 5138-5140 (2009)

498. T. Nitabaru, A. Nojiri, M. Kobayashi, N. Kumagai, and M. Shibasaki

anti-Selective Catalytic Asymmetric Nitroaldol Reaction via a Heterobimetallic Heterogeneous Catalyst

J. Am. Chem. Soc., 131, 13860-13869 (2009)

499. T. Mashiko, N. Kumagai, and M. Shibasaki 
Managing Highly Coordinative Substrates in Asymmetric Catalysis: A Catalytic Asymmetric Amination with a Lanthanum-Based Ternary Catalyst

J. Am. Chem. Soc., 131, 14990-14999 (2009)

500. M. Shibasaki, N. Kumagai and T. Mashiko

Inventing and Understanding Catalytic, Enantioselective Reactions

Curr. Opin. Drug Discov. Dev., 12, 862-875 (2009)

501. T. Yoshino, H. Morimoto, G. L. S. Matsunaga and M. Shibasaki

Construction of Contiguous Tetrasubstituted Chiral Carbon Stereocenters via Direct Catalytic Asymmetric Aldol Reaction of $\alpha$-Isothiocyanato Esters with Ketones

J. Am. Chem. Soc., 131, 17082-17083 (2009)

502. M. Iwata, R. Yazaki, Y. Suzuki, N. Kumagai and M. Shibasaki

Direct Catalytic Asymmetric Aldol Reaction of Thioamides: Toward a Stereocontrolled Synthesis of 1,3-Polyols

J. Am. Chem. Soc., 131, 18244-18245 (2009)

503. Y. Shimizu, S.-L. Shi, H. Ususda, M. Kanai and M. Shibasaki

Catalytic Asymmetric Total Synthesis of ent-Hyperforin

Angew. Chem. Int. Ed., 49, 1103-1106 (2010)

504. M. Furutachi, Z. Chen, S. Matsunaga and M. Shibasaki

Catalytic Asymmetric 1,4-Additions of $\beta$-Keto Esters to Nitroalkenes Promoted by a Bifunctional Homobimetallic $\mathrm{CO}_{2}$-Schiff Base Complex

Molecules, 15, 532-544 (2010)

505. S. Mouri, M. Furutachi, Z. Chen, H. Mitsunuma, S. Matsunaga and M. Shibasaki

Catalytic Asymmetric Synthesis of 3-Aminooxindoles: Enantiofacial Selectivity Switch in Bimetallic vs Monometallic Schiff Base Catalysis

J. Am. Chem. Soc., 132, 1255-1257 (2010)

506. N. E. Shepherd, H. Tanabe, Y. Xu, S. Matsunaga and M. Shibasaki

Direct Catalytic Asymmetric Vinylogous Mannich-type and Michael Reactions of an $\alpha, \beta$-Unsaturated $\gamma$-Butyrolactam Under Dinuclear Nickel Catalysis

J. Am. Chem. Soc., 132, 3666-3667 (2010)

507. S. Handa, V. Gnanadesikan, S. Matsunaga and M. Shibasaki

Heterobimetallic Transition Metal/Rare Earth Metal Bifunctional Catalysis: a Cu-Sm-Schiff Base Complex for syn-Selective Catalytic Asymmetric Nitro-Mannich Reaction

J. Am. Chem. Soc., 132, 4925-4934 (2010)

508. A. Matsuzawa, A. Nojiri, N. Kumagai and M. Shibasaki

Solvent-depebdent Self-discrimination of Bis(2-hydroxyphenyl)amides

Chem. Eur. J., 16, 5036-5042 (2010)

509. Y. Kawato, N. Takahashi, N. Kumagai and M. Shibasaki

Catalytic Asymmetric Conjugate Addition of $\alpha$-Cyanoketones for the Construction of a Quarternary Stereogenic Center

Org. Lett., 12, 1484-1487 (2010)

510. S. Handa, V. Gnanadesikan, S. Matsunaga and M. Shibasaki

Heterobimetallic Transition Metal/Rare Earth Metal Bifunctional Catalysis: a Cu-Sm-Schiff Base Complex for syn-Selective Catalytic Asymmetric Nitro-Mannich Reaction 
J. Am. Chem. Soc., 132, 4925-4934 (2010)

511. T. Nitabaru, N. Kumagai and M. Shibasaki

Catalytic Asymmetric Nitro-Mannich Reactions with a Yb/K Heterobimetallic Catalyst

Molecules, 15, 1280-1290 (2010)

512. R. Yazaki, N. Kumagai and M. Shibasaki

Direct Catalytic Asymmetric Addition of Allyl Cyanide to Ketones via Soft Lewis Acid/Hard Brønsted Base/Hard Lewis Base Catalysis

J. Am. Chem. Soc., 132, 5522-5531 (2010)

513. S.-L. Shi, L.-W. Xu, K. Oisaki, M. Kanai and M. Shibasaki

Identification of Modular Chiral Bisphosphines Effective for $\mathrm{Cu}(\mathrm{I})$-Catalyzed Asymmetric Allylation and Proprargylation of Ketones

J. Am. Chem. Soc., 132, 6638-6639 (2010)

514. M. Iwata, R. Yazaki, N. Kumagai and M. Shibasaki

Direct Catalytic Asymmetric Aldol Reaction of Thioamides: a Concise Asymmetric Synthesis of $(R)$-Fluoxetine

Tetrahedron: Asymmetry, 21, 1688-1694 (2010)

515. Y. Saga, R. Motoki, S. Makino, Y. Shimizu, M. Kanai and M. Shibasaki

Catalytic Asymmetric Synthesis of R207910

J. Am. Chem. Soc., 132, 7905-7907 (2010)

516. R. Yazaki, N. Kumagai and M. Shibasaki

Direct Catalytic Asymmetric Conjugate Addition of Terminal Alkynes to $\alpha, \beta$-Unsatutated Thioamides

J. Am. Chem. Soc., 132, 10275-10277 (2010)

517. Y. Tanaka, M. Kanai and M. Shibasaki

Catalytic Enantioselective Construction of $\beta$-Quaternary Carbons via Conjugate Addition of Cyanide to $\beta, \beta$-Disubstituted, $\alpha, \beta$-Unsaturated Cabonyl Compounds

J. Am. Chem. Soc., 132, 8862-8863 (2010)

518. Y. Shimizu, S,-L. Shi, H. Usuda, M. Kanai and M. Shibasaki

The First Catalytic Asymmetric Total Synthesis of ent-Hyperforin

Tetrahedron, 66, 6569-6584 (2010)

519. T. Yukawa, B. Seelig, Y. Xu, H. Morimoto, S. Matsunaga, A. Berkessel and M. Shibasaki

Catalytic Asymmetric Aza-Morita-Baylis-Hillman Reaction of Methyl Acrylate: Role of a Bifunctional $\mathrm{La}(\mathrm{O}-i \mathrm{Pr})_{3} /$ Linked-BINOL Complex

J. Am. Chem. Soc., 132, 11988-11992 (2010)

520. I.-H. Chen, M. Kanai and M. Shibasaki

Copper(I)-Secondary Diamine Complex-Catalyzed Enantioselective Conjugate Boration of Linear $\beta, \beta$-Disubstituted Enones

Org. Lett., 12, 4098-4101 (2010)

521. Y. Xu, S. Matsunaga and M. Shibasaki

syn-Selective Catalytic Asymmetric 1,4-Additionn of $\alpha$-Ketoanilides to Nitroalkenes under Dinuclear Nickel Catlysis

Org. Lett., 12, 3246-3249 (2010) 
522. M. Furutachi, S. Mouri, S. Matsunaga, and M. Shibasaki

A Heterobimetallic Ni/La-salan Complex for Catalytic Asymmetric Decarboxylative 1,4-Addition of Malonic Acid Half-Thioester

Chem. Asian J., 5, 2351-2354 (2010)

523. M. Shibasaki and M. Matsunaga

Bifunctional Asymmetric Catalysis Based on Dinuclear Schiff Base Complexes

J. Synth. Org. Chem. Jpn., 68, 1142-1149 (2010)

524. F. Berhal, S. Takechi, N. Kumagai and M. Shibasaki

Catalytic Asymmetric Amination of $N$-Nonsubstituted $\alpha$-Alkoxycarbonyl Amides: Concise Enantioselective Total Synthesis of Mycestericin F and G

Chem. Eur. J., 17, 1915-1921 (2011)

525. S. Takechi, N. Kumagai and M. Shibasaki

Catalytic Asymmetric Hydroxylation of $\alpha$-Alkoxycarbonyl Amides with a $\operatorname{Pr}(\mathrm{O} i \mathrm{Pr}) 3 /$ Amide-Based Ligand Catalyst

Tetrahedron Lett., 52, 2140-2143 (2011)

526. R. Yazaki, N. Kumagai and M. Shibasaki

Enantioselective Synthesis of a GPR40 Agonist AMG 837 via Catalytic Asymmetric Conjugate Addition of Terminal Alkyne to $\alpha, \beta$-Unsaturated Thioamide

Org. Lett., 13, 952-955 (2011)

527. M. Shibasaki, M. Kanai and K. Yamatsugu

Recent Development in Synthetic Strategies for Oseltamivir Phosphate

Isr. J. Chem., 51, 316-328 (2011)

528. N. Kumagai and M. Shibasaki

Recent Advances in Direct Catalytic Asymmetric Transformations under Proton Transfer Conditions

Angew. Chem. Int. Ed., 50, 4760-4772 (2011)

529. M. Iwata, R. Yazaki, I. H. Chen, D. Sureshkumar, N. Kumagai and M. Shibasaki

Direct Catalytic Enantio- and Diastereoselective Aldol Reaction of Thioamides

J. Am. Chem. Soc., 133, 5554-5560 (2011)

530. Y. Xu, L. Lin, M. Kanai, S. Matsunaga and M. Shibasaki

Catalytic Asymmetric Ring-Opening of meso-Aziridines with Malonates under Heterodinuclear Rare Earth Metal Schiff Base Catalysis

J. Am. Chem. Soc., 133, 5791-5793 (2011)

531. G. Lu, T. Yoshino, H. Morimoto, S. Matsunaga and M. Shibasaki

Stereodivergent Direct Catalytic Asymmetric Mannich-type Reactions of $\alpha$-Isothiocyanato Ester with Ketimines

Angew. Chem. Int. Ed., 50, 4382-4385 (2011)

532. R. Yazaki, N. Kumagai, and M. Shibasaki

Cooperative Activation of Alkyne and Thioamide Functionalities; Direct Catalytic Asymmetric Conjugate Addition of Terminal Alkynes to $\alpha, \beta$-Unsaturated Thioamides

Chem. Asian J., 6, 1778-1790 (2011)

533. Y. Kawato, M. Iwata, R. Yazaki, N. Kumagai and M. Shibasaki

A Simplified Catalytic System for Direct Catalytic Asymmetric Aldol Reaction of Thioamides; 
Application to an Enantioselective Synthesis of Atorvastatin Tetrahedron, 65, 6539-6546 (2011)

534. A. Matsuzawa, T. Mashiko, N. Kumagai and M. Shibasaki

La/Ag Heterobimetallic Cooperative Catalysis; Catalytic Asymmetric Conia-Ene Reaction Angew. Chem. Int. Ed., 50, 7616-7619 (2011)

535. Y. Yanagida, R. Yazaki, N. Kumagai and M. Shibasaki

Asymmetric Synthesis of Isothiazoles through $\mathrm{Cu}$ Catalysis: Direct Catalytic Asymmetric Conjugate Addition of Allyl Cyanide to $\alpha, \beta$-Unsaturated Thioamides

Angew. Chem. Int. Ed., 50, 7910-7914 (2011)

536. Y. Suzuki, R. Yazaki, N. Kumagai and M. Shibasaki

Direct Catalytic Asymmetric Intramolecular Conjugate Addition of Thioamide to $\alpha, \beta$-Unsaturated Ester

Chem. Eur. J., 17, 11998-12001 (2011)

537. L. Yin, M. Kanai, and M. Shibasaki

"A Facile Pathway to Enantiomerically Enriched 3-Hydroxy-2-Oxindoles: Asymmetric Intramolecular Arylation of $\alpha$-Keto Amides Catalyzed by a Palladium-DifluorPhos Complex" Angew. Chem. Int. Ed., 50, 7620-7623 (2011)

538. T. Ogawa, S. Mouri, R. Yazaki, N. Kumagai, and M. Shibasaki

Intermeiate as Catalyst: Catalytic Asymmetric Conjugate Addition of Nitroalkanes to $\alpha, \beta$-Unsaturated Thioamides

Org. Lett., 14, 110-113 (2012)

539. S. Mouri, Z. Chen, S. Matsunaga, and M. Shibasaki

Catalytic Asymmetric Amination of Oxindoles under Dinuclear Nickel Schiff Base Catalysis

Heterocycles, 84, 879-892 (2012)

540. T. Sone, A. Yamaguchi, S. Matsunaga, and M. Shibasaki

Enantioselective Synthesis of 2,2-Disubstituted Terminal Epoxides via Catalytic Asymmetric Corey-Chaykovsky Epoxidation of Ketones

Molecules, 17, 1617-1634 (2012)

541. T. Nitabaru, N. Kumagai, and M. Shibasaki

Catalytic Asymmetric anti-Selective Nitroaldol Reaction En Route to Zanamivir

Angew. Chem. Int. Ed., 51, 1644-1647 (2012)

542. A. Nojiri, N. Kumagai, and M. Shibasaki

Reversible Heterochiral Aggregation/Dissociation of Bis(2-hydroxyphenyl)diamides Driven by $\mathrm{UV} / \mathrm{V}$ is Irradiation

Angew. Chem. Int. Ed., 51, 2137-2141 (2012)

543. S. Takechi, S. Yasuda, N. Kumagai, and M. Shibasaki

A Direct Catalytic Asymmetric Aldol Reaction of $\alpha$-Sulfanyl Lactones: Efficient Synthesis of SPT Inhibitors

Org. Lett., 14, 3108-3111 (2012)

544. Y. Suzuki, M. Iwata, R. Yazaki, N. Kumagai, and M. Shibasaki

Concise Enantioselective Synthesis of Duloxetine via Direct Catalytic Asymmetric Aldol Reaction of Thioamide

J. Org. Chem., 77, 4496-4500 (2012) 
545. P. Gopinath, T. Watanabe, and M. Shibasaki

Catalytic Enantioselective Desymmetrization of meso-Glutaric Anhydrides Using a Stable $\mathrm{Ni}_{2}$-Schiff Base Catalyst

Org. Lett., 5, 1358-1361 (2012)

546. D. Sureshkumar, Y. Kawato, M. Iwata, N. Kumagai, and M. Shibasaki

anti-Selective Direct Catalytic Asymmetic Aldol Reaction of Thiolactams

Org. Lett., 14, 3108-3111 (2012)

547. H. Mitsunuma, M. Shibasaki, M. Kanai, and S. Matsunaga

Catalytic Asymmetric Total Synthesis of Chimonanthine, Folicanthine, and Calycanthine through Double Michael Reaction of Bisoxindole

Angew. Chem. Int. Ed., 51, 5217-5221 (2012)

548. S. Kato, T. Yoshino, M. Shibasaki, M. Kanai, and S. Matsunaga

Catalytic Asymmetric Synthesis of Spirooxindoles by a Mannich-type Reaction of Isothiocyanato Oxindoles

Angew. Chem. Int. Ed., 51, 7007-7010 (2012)

549. N. Kumagai and M. Shibasaki

Cooperative Asymmetric Catalysis Using Thioamides toward Truly Organic Syntheses

Isr. J. Chem., 52, 604-612 (2012)

550. T. Ogawa, N. Kumagai, and M. Shibasaki

Catalytic Asymmetric Conjugate Addition of Thiols to $\alpha, \beta$-Unsaturated Thioamides: Expeditious Access to Enantioenriched 1,5-Benzothiazepines

Angew. Chem. Int. Ed., 51, 8551-8555 (2012)

551. T. Kimura, S. Kanagaki, Y. Matsui, M. Imoto, T. Watanabe and M. Shibasaki

Synthesis and Assignment of the Absolute Configuration of Indenotryptoline Bisindole Alkaloid BE-54017

Org. Lett., 17, 4418-4421 (2012)

552. P. Gopinath, T. Wtanabe and M. Shibasaki

Studies on Catalytic Enantioselective Total Synthesis of Caprazamycin B: Construction of the Western Zone

J. Org. Chem., 77, 9260-9267 (2012)

553. S. Yasuda, N. Kumagai, and M. Shibasaki

Direct Asymmetric $\alpha$-Allylation of Ketones with Allylic Alcohols via Pd/Enamine Cooperative Function

Heterocycles, 86, 745-757 (2012)

554. N. Kumagai and M. Shibasaki

Asymmetric Catalysis with Bis(hydroxyphenyl)diamides/Rare-Earth Metal Complexes

Angew. Chem. Int. Ed., 52, 223-234 (2013)

555. L. Yin, Y. Otsuka, H. Takada, S. Mouri, R. Yazaki, N. Kumagai and M. Shibasaki

Direct Catalytic Asymmetric Alkynylatiion of Ketoimines

Org. Lett., 15, 698-701 (2013)

556. Y. Otsuka, H. Takada, S. Yasuda, N. Kumagai, and M. Shibasaki

Direct Catalytic Asymmetric Addition of Allylic Cyanides to Aldehydes for Expeditious Access to Enantioenriched Unsaturated $\delta$-Valerolactones 
Chem. Asian J., 8, 354-358 (2013)

557. S. Matsunaga and M. Shibasaki

Multimetallic Schiff Base Complexes as Cooperative Asymmetric Catalysts

Synthesis, 45, 421-437 (2013)

558. N. Kumagai and M. Shibasaki

Catalytic Chemical Transformations with Conformationally Dynamic Catalytic Systems

Cat. Sci. Technol., 3, 41-57 (2013)

559. Y. Kawato, S. Chaudhary, N. Kumagai, and M. Shibasaki

Streamlined Catalytic Asymmetric Synthesis of Atorvastatin

Chem. Eur. J., 19, 3802-3806 (2013)

560. K. Alagiri, M. Furutachi, K. Yamatsugu, N. Kumagai, T. Watanabe, and M. Shibasaki

Two Approaches toward the Formal Total Synthesis of Oseltamivir Phosphate (Tamiflu): Catalytic Enantioselective Three-Component Reaction Strategy and L-Glutamic Acid Strategy

J. Org. Chem., 8, 4019-4026 (2013)

561. A. Nojiri, N. Kumagai, and M. Shibasaki

In Situ Manipulation of Catalyst Performance via the Photocontrolled Aggregation/Dissociation State of the Catalyst

Chem. Commun., 49, 4628-4630 (2013)

562. H. Abe, M. Kawada, H. Inoue, S. Ohba, A. Nomoto, T. Watanabe, and M. Shibasaki Synthesis of Intervenolin, an Antitmor Natural Quinolone with Unusual Substituents Org. Lett., 15, 2124-2127 (2013)

563. M. Hiasa, Y. Isoda, Y. Kishimoto, K. Saitoh, Y. Kimura, M. Kanai, M. Shibasaki, D. Hatakeyama, Y. Kirinoand and T. Kuzuhara

Inhibition of MAO-A and Stimulation of Behavioural Activities in Mice by the Inactive Prodrug Form of the anti-Influenza Agent Oseltamivir

British J. Pharm., 169, 115-129 (2013)

564. S. Takechi, N. Kumagai, and M. Shibasaki

Direct Catalytic Asymmetric Mannich-type Reaction of $\alpha$-Sulfanyl Lactones

Org. Lett., 11, 2632-2635 (2013)

565. T. Ogawa, N. Kumagai, and M. Shibasaki

Self-Assembling Neodymium/Sodium Heterobimetallic Asymmetric Catalyst Confined in a Carbon Nanotube Network

Angew. Chem. Int. Ed., 52, 6196-6201 (2013)

566. L. Yin, H. Takada, N. Kumagai, and M. Shibasaki

Direct Catalytic Asymmetric Vinylogous Mannich-type Reaction of $\boldsymbol{\gamma}$-Butenolides with Ketimines Angew. Chem. Int. Ed., 52, 7310-7313 (2013)

567. L. Yin, Y. Bao, N. Kumagai, and M. Shibasaki

Catalytic Asymmetric Hydrophosphonylation of Ketimines

J. Am. Chem. Soc., 135, 10338-10341 (2013)

568. N. Kumagai, and M. Shibasaki

A State-of-the-Art Asymmetric Catalyst for Enantioselective Synthesis of Therapeutics

Chemistry, 12-17 (2013) 
569. H. Abe, M. Kawada, H. Inoue, S. Ohba, T. Masuda, C. Hayashi, M. Igarashi, A. Nomoto, T. Watanabe, and M. Shibasaki

Structure-Activity Relationship Study of Intervenolin Derivatives: Synthesis, Antitumor, and anti-Helicobacter pylori Activities

Tetrahedron, 69, 7608-7617 (2013)

570. Y. Kawato, N. Kumagai, and M. Shibasaki

Direct Catalytic Asymmetric Addition of Acetonitrile to $N$-Thiophosphinoylimines

Chem. Commun., 49, 11227-11229 (2013)

571. K. Tamura, M. Furutachi, N. Kumagai, and M. Shibasaki

An Enantioselective Synthesis of Voriconazole

J. Org. Chem., 78, 11396-11403 (2013)

572. D. Sureshkumar, K. Hashimoto, N. Kumagai, and M. Shibasaki

A Modified Preparation Procedure for Carbon Nanotube-Confined $\mathrm{Nd} / \mathrm{Na}$ Heterobimetallic Catalyst for anti-Selective Catalytic Asymmetric Nitroaldol Reactions

J. Org. Chem., 78, 11494-11500 (2013)

573. S. Matsunaga and M. Shibasaki

Recent Advances in Cooperative Bimetallic Asymmetric Catalysis: Dinuclear Schiff Base Complexes

Chem. Commun., 50, 1044-1057 (2014)

574. A. Matsuzawa, C. Opie, N. Kumagai, and M. Shibasaki

Direct Aldol Strategy in Enantioselective Total Synthesis of Thuggacin B

Chem. Eur. J., 20, 68-71 (2014)

575. K. Tamura, N. Kumagai, and M. Shibasaki

An Enantioselective Synthesis of the Key Intermediate for Triazole Antifungal Agents; Application to the Catalytic Asymmetric Synthesis of Efinaconazole (Jublia)

J. Org. Chem., 79, 3272-3278 (2014)

576. A. Saito, N. Kumagai, and M. Shibasaki

Concise Enantioselective Synthesis of $\delta, \delta$-Disubstituted $\delta$-Valerolactones

Tetrahedron Lett., 55, 3167-3171 (2014)

577. L. Yin, H. Takada, S. Lin, N. Kumagai, and M. Shibasaki

Direct Catalytic AsymmetricVinylogous Conjugate Addition of Unsaturated Butyrolactones to $\alpha, \beta$-Unsaturated Thioamides

Angew. Chem. Int. Ed., 53, 5327-5331 (2014)

578. K. Weidner, N. Kumagai, and M. Shibasaki

A Designed Amide as an Aldol Donor in the Direct Catalytic Asymmetric Aldol Reaction

Angew. Chem. Int. Ed., 53, 6150-6154 (2014)

579. P. Gopinath, L. Wang, H. Abe, G. Ravi, T. Masuda, T. Watanabe, and M. Shibasaki

Catalytic Asymmetric Total Synthesis of (+)-Caprazol

Org. Lett., 16, 3364-3367 (2014)

580. K. Hashimoto, N. Kumagai, and M. Shibasaki

Self-Assembled Asymmetric Catalyst Engaged in a Continuous-Flow Platform: An anti-Selective Catalytic Asymmetric Nitroaldol Reaction

Org. Lett., 16, 3496-3499 (2014) 
581. K. Alagiri, S. Lin, N. Kumagai, and M. Shibasaki

Iterative Direct Aldol Strategy for Polypropionates: Enantioselective Total Synthesis of $(-)$-Membrenone A and B

Org. Lett., 16, 5301-5303 (2014)

582. Y. Bao, N. Kumagai, and M. Shibasaki

Design and Synthesis of a Bis(hydroxyphenyl)diamide Bearing a Pendant Thiazolium Unit; Application to the Catalytic Asymmetric Intramolecular Stetter Reaction

Tetrahedron: Asymmetry, 25, 1401-1408 (2014)

583. M. Furutachi, N. Kumagai, T. Watanabe, and M. Shibasaki

Chromatography-Free Synthesis of Corey's Intermediate for Tamiflu

Tetrahedron, 70, 9113-9117 (2014)

584. L. Yin, L. Brewitz, N. Kumagai, and M. Shibasaki

Catalytic Generation of $\alpha-\mathrm{CF}_{3}$ Enolate: Direct Catalytic Asymmetric Mannich-type Reaction of $\alpha-\mathrm{CF}_{3}$ Amide

J. Am. Chem. Soc., 136, 17958-17961 (2014)

585. D. Sureshkumar, V. Ganesh, N. Kumagai, and M. Shibasaki

Direct Catalytic Addition of Alkylnitriles to Aldehydes by Transition-Metal/NHC Compounds

Chem. Eur. J., 20, 15723-15726 (2014)

586. Y. Xu, K. Kaneko, M. Kanai, M. Shibasaki and S. Matsunaga.

Regiodivergent Kinetic Resolution of Terminal and Internal rac-Aziridines with Malonates under Dinuclear Schiff Base Catalysis

J. Am. Chem. Soc., 136, 9190-9194 (2014)

587. N. Kumagai and M. Shibasaki

Recent Advances in Catalytic Asymmetric C-C Bond-Forming Reactions to Ketimines Promoted by Metal-Based Catalysts

Bull. Chem. Soc. Jpn., 88, 503-517 (2015)

588. K. Hashimoto, N. Kumagai, and M. Shibasaki

A Carbon Nanotube Confinement Strategy to Implement Homogeneous Asymmetric Catalysis in the Solid Phase

Chem. Eur. J., 21, 4262-4266 (2015)

589. S. Lin, Y. Kawato, N. Kumagai, and M. Shibasaki

Catalytic Asymmetric Mannich-type Reaction of $N$-Alkylidene- $\alpha$-Aminoacetonitrile with Ketimines

Angew. Chem. Int. Ed., 54, 5183-5186 (2015)

590. K. Weidner, Z. Sun, N. Kumagai, and M. Shibasaki

Direct Catalytic Asymmetric Aldol Reaction of $\alpha-\mathrm{N}_{3}$ Amide

Angew. Chem. Int. Ed., 54, 6236-6240 (2015)

591. K. Tamura, N. Kumagai, and M. Shibasaki

Ddirect Catalytic Asymmetric Mannich-type Reaction of Benzyl Isocyanide: Stereoselective Synthesis of 1,2-Diarylethylenediamines

Eur. J. Org. Chem., 3026-3031 (2015)

592. H. Abe, P. Gopinath, G. Ravi, L. Wang, T. Watanabe, and M. Shibaaki

Synthesis of Caprazamycin B 
Tetrahadron Lett., 56, 3782-3785 (2015)

593. H. Abe, C. Sakashita, M. Kawada, A. Nomoto, T. Watanabe, and M. Shibasaki

Synthesis and Structure-Activity Relationship Study of NBR116716B, an Antitumor Natural Product

Chem. Pharm. Bull., 63, 463-468 (2015)

594. N. Majumdar, A. Saito, L. Yin, N. Kumagai, and M. Shibasaki

Direct Catalytic Asymmetric Conjugate Addition of Saturated and Unsaturated Thioamides

Org. Lett., 17, 3363-3365 (2015)

595. Y. Bao, N. Kumagai, and M. Shibasaki

Managing the Retro-Pathway in Direct Catalytic Asymmetric Aldol Reactions of Thioamides

Chem. Sci., 6, 6124-6132 (2015)

596. H. Takada, N. Kumagai, and M. Shibasaki

Stereoselective Total Synthesis of KAE609 via Direct Catalytic Asymmetric Alkynylation to Ketimine

Org. Lett., 19, 4762 (2015)

597. M. Zhang, S. Wada, F. Amemiya, T. Watanabe, and M. Shibasaki

Synthesis and Determination of Absolute Configuration of Lentztrehalose A

Chem. Pharm. Bull., 63, 961-966 (2015)

598. Z. Sun, K. Weidner, N. Kumagai, and M. Shibasaki

Direct Catalytic Asymmetric Mannich-type Reaction of $\alpha-\mathrm{N}_{3}$ Amide

Chem. Eur. J., 21, 17574-17577 (2015)

599. L. Bewitz, F. A. Arteaga, L. Yin, K. Alagiri, N. Kumagai, and M. Shibasaki

Direct Catalytic Asymmetric Mannich-type Reaction of $\alpha$ - and $\beta$-Fluorinated Amides

J. Am. Chem. Soc., 137, 15929-15939 (2015)

600. D. Tatsuda, I. Momose, T. Someno, R. Sawa, Y. Kubota, M. Iijima, T. Kunisada, T. Watanabe, M. Shibasaki and A. Nomoto

Quinofuracins A-E, Produced by the Fungus Staphylotrichum Boninense PF1444, Show p53-Dependent Growth Suppression.

J. Nat. Prod., 78, 188-195 (2015)

601. J. Cui, T. Watanabe, and M. Shibasaki

Catalytic Asymmetric Synthesis of Key Intermediate for Scytophycin C

Tetrahedron Lett., 57, 446-448 (2016)

602. S. Lin, M. Kumagai and M. Shibasaki

Direct Catalytic Asymmetric Mannich-type Reaction of $\alpha, \beta$-Unsaturated $\gamma$-Butyrolactam with Ketimines

Chem. Eur. J., 22, 3296-3299 (2016)

603. A. Nonoyama, K. Hashimoto, A. Saito, N. Kumagai, and M. Shibasaki

Preparation of $\mathrm{Nd} / \mathrm{Na}$ Heterogeneous Catalyst from Bench-Stable and Inexpensive Nd Salt for an anti-Selective Catalytic Asymmetric Nitroaldol Reaction

Tetrahedron Lett., 57, 1815-1819 (2016)

604. M. Zhang, N. Kumagai, and M. Shibasaki

Electrophilic Activation of $\alpha, \beta$-Unsaturated Amides: Catalytic Asymmetric Vinylogouse 
Conjugate Addition of Unsaturated $\gamma$-Butyrolactones

Chem. Eur. J., 22, 5525-5529 (2016)

605. F. A. Arteaga, Z. Liu, L. Brewitz, J. Chen, B. Sun, N. Kumagai, and M. Shibasaki

Direct Catalytic Asymmetric Mannich-type Reaction of Alkylamides

Org. Lett., 18, 2391-2394 (2016)

606. D. Tatsuda, M. Amemiya, R. Sawa, K. Sumiyoshi, T. Watanabe, I. Momose, M. Kawada, A. Nomoto and M. Shibasaki

Coccoquinones A and B, New Anthraquinone Derivatives Produced by Staphylotrichum coccosporum PF1460

J. Antibiot., 69, 176-178 (2016)

607. T. Takeuchi, H. Abe, T. Watanabe and M. Shibasaki

Catalytic Asymmetric Synthesis of CPZEN-45

Tetrahedron Lett., 57, 2901-2904 (2016)

608. H. Abe, Y. Yamazaki, C. Sakashita, I. Momose, T. Watanabe and M. Shibasaki Synthesis of Androprostamine A and Resormycin

Chem. Pharm. Bull., 64, 982-987 (2016)

609. N. Kumagai and M. Shibasaki

Nucleohilic and Eletrophilic Activation of Non-Heteroaromatic Amides in Atom-Economical Asymmetric Catalysis

Chem. Eur. J., 22, 15192-15200 (2016)

610. S. Lin, N. Kumagai, and M. Shibasaki

Enantioselective Synthesis of $\alpha, \alpha$-Disubstituted $\alpha$-Amino Acids via Direct Catalytic Asymmetric Addition of Acetonitrile to $\alpha$-Iminoesters

Org. Biomol. Chem., 14, 9725-9730 (2016)

611. Y. Sahara, J. Cui, M. Furutachi, J. Chen, T. Watanabe, and M. Shibasaki

Catalytic Asymmetric Synthesis of the C1-C15 Segment of Spirastellolide A.

Synthesis, 49, 69-75 (2017)

612. S. Adachi, N. Kumagai, and M. Shibasaki

Pyramidalization/Twisting of the Amide Functionality via Remote Steric Congestion Triggered by Metal Coordination

Chem. Sci., 8, 85-90 (2017)

613. L. Brewitz, N. Kumagai, and M. Shibasaki

Catalytic Asymmetric Synthesis of 2,3,3,3-Tetrafluoro-2-Methyl-1-Arylpropan-1-Amines as Useful Building Blocks for SAR-Studies

J. Fluorine Chem., 194, 1-7 (2017) 